\title{
Identification of differentially expressed proteins involved in fetal scarless wound healing using a rat model of cleft lip
}

\author{
YU YAN ${ }^{1-3}$, HONG LIU ${ }^{2}$, JIARONG YI $^{3}$, ZIZI CHEN ${ }^{3}$, JIA CHEN $^{3}$, JIANFEI ZHANG ${ }^{4}$,

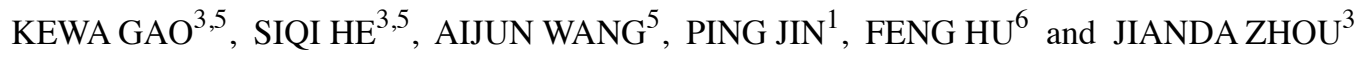 \\ ${ }^{1}$ Department of Endocrinology, The Third Xiangya Hospital, Central South University, Changsha, Hunan 410013; \\ ${ }^{2}$ Department of Nephrology, The Second Xiangya Hospital, Central South University, Changsha, Hunan 410011; \\ ${ }^{3}$ Department of Plastic and Reconstructive Surgery, The Third Xiangya Hospital, Central South University, \\ Changsha, Hunan 410013; ${ }^{4}$ Department of Burns and Plastic Surgery, The Second Hospital of South China University, \\ Hengyang, Hunan 421000, P.R. China; ${ }^{5}$ Department of Surgery, Surgical Bioengineering Laboratory, \\ University of California Davis, Sacramento, CA 95817, USA; ${ }^{6}$ Department of Dermatology, Hunan People's Hospital, \\ The First Affiliated Hospital of Hunan Normal University, Changsha, Hunan 410000, P.R. China
}

Received May 6, 2020; Accepted December 7, 2020

DOI: $10.3892 / \mathrm{mmr} .2021 .12235$

\begin{abstract}
In early pregnancy, fetal skin wounds can heal quickly and undergo a transition period from scarless healing to scar formation. The aim of the present study was to identify potential biomarkers associated with scarless repair of cleft lips, in order to determine the intrinsic factors leading to scar formation in embryonic tissue. A stable model of cleft lip was established using microsurgery by constructing a wedge-shaped cleft lip-like defect in fetal rats at gestational age (GA) 16.5 and GA18.5. The GA16.5 and GA18.5 groups were used to model scarless healing and scar formation, respectively. The fetuses were returned to the uterus following surgery, then removed $72 \mathrm{~h}$ after the procedure. Macroscopic observation of the cleft defect and histological examination were carried out. Reverse transcription-quantitative (RT-q) PCR and parallel reaction monitoring (PRM) were used to detect mRNA and protein expression levels, respectively. The upper-left lip completely healed $72 \mathrm{~h}$ after surgery in the GA16.5 group of fetal rats. However, this was not the case in the GA18.5 group. Histological examination indicated new follicles visible under the epidermis of the
\end{abstract}

Correspondence to: Dr Jianda Zhou, Department of Plastic and Reconstructive Surgery, The Third Xiangya Hospital, Central South University, 138 Tongzipo Road, Changsha, Hunan 410013, P.R. China

E-mail: zhoujianda@csu.edu.cn

Dr Feng Hu, Department of Dermatology, Hunan People's Hospital, The First Affiliated Hospital of Hunan Normal University, 61 Western Jiefang Road, Changsha, Hunan 410000, P.R. China E-mail: doctorzhoujianda@163.com

Key words: cleft lip, scarless healing, label-free quantification, proteomics, parallel reaction monitoring scarless group (GA16.5). Scarring was visible on the upper-left cleft lip wound of the fetal rats in the GA18.5 group. The expression of some growth and pro-inflammatory factors, including TNF- $\alpha$, were also different between two groups. Label-free quantification was used to identified differentially expressed proteins and five differentially expressed proteins (Smad4, Fabp5, S100a4, S100a8 and S100a9) were identified. The relative expression of these molecules at the mRNA and protein levels were measured using RT-qPCR and PRM. These molecules may represent potential biomarkers for the scarless repair of fetal rat cleft lip wounds.

\section{Introduction}

The cleft lip is a very common congenital oral and maxillofacial malformation, of ten accompanied by cleft palate and alveolar cleft. Although surgical repair techniques are continuously being improved, numerous patients still experience inevitable secondary scar formation after surgery. In recent years, with the development of prenatal diagnosis and treatment technology (1), intrauterine surgery has made it possible to correct developmental deformities, such as a cleft lip.

The concept of scarless healing was first proposed by Burrington (2) in 1971. It was later observed that fetal skin wounds that occur during early pregnancy can heal quickly and restore intact skin barrier functions. In contrast, fetal skin damage that occurs in the third trimester of pregnancy can result in the formation of scar tissue similar to that of an adult (3). Therefore, the different manifestations of scarless healing of mammalian fetal wounds are related to the gestational age of the fetus (4). Dang et al (5) and Longaker et al (6) demonstrated that this transition period from scarless healing to scar formation occurred between day 16.5 of gestational age (GA) and GA18.5 in rats and mice, which have a gestation period of $\sim 21.5$ days. Lorenz et al (7) and Cass et al (8) suggested that when 1-2 mm incisions are inflicted on fetal rats, the transition 
period of scarless healing to healing with scar formation was still between 16.5 (GA16.5) and 18.5 days (GA18.5).

This phenotypic difference in fetal wounds has inspired further examination of the specific underlying mechanisms. Initially, it was hypothesized that the reason for early scar repair was that the fetus developed in amniotic fluid, which is rich in growth factors and extracellular matrix (ECM) components $(9,10)$. Previous studies typically utilized large animal models to study the presence of scars following repair $(11,12)$. However, only a few studies have reported the use of a fetal rat cleft lip wound model to establish the effectiveness of surgical repair at different gestational ages. Moreover, due to the short gestation period of rats, the experimental cycle can be shortened, and the experiment can therefore be repeated.

Given the importance of this process, the present study, screened out several specific markers of early fetal scarless repair. The present study aimed to gain insight into the occurrence and mechanisms of scarless repair, and to identify new clinical targets for the prevention and treatment of scars.

\section{Materials and methods}

Animals. A total of 36 SPF-grade adult Sprague-Dawley (SD) rats (female; mean weight, $250 \mathrm{~g}$; age, 12 weeks) were obtained from the Third Xiangya Hospital of Central South University Animal Experiment Center (Hunan, China) and divided into two groups that received surgery once their fetuses reached GA16.5 or GA18.5, respectively ( $\mathrm{n}=18$ each). The following housing conditions were implemented: A temperature between $25 \pm 2^{\circ} \mathrm{C}$, relative humidity of $55 \pm 15 \%$, ventilation rate of 10-20 times per hour, time-controlled artificial lighting (12-h day-night cycle) and ad libitum access to food and water. The experiments were supervised throughout and were performed in accordance with animal experimentation ethics.

Preliminary study on different repair modes applicable to fetal rats with artificial cleft lip wounds. Fetal rats located away from the uterine horn were selected to prevent subsequent abortion, as described previously (13). In the current study, rats were anesthetized with $30 \mathrm{mg} / \mathrm{kg}$ pentobarbital sodium intraperitoneally before surgery. A wedge-shaped cleft-like defect was created on the upper-left lip of the fetal rats. The upper-right lip did not receive any treatment and was used as a control condition. The fetal rats were then returned to the uterus. Fetal rats from the GA16.5 and GA18.5 groups were then removed three days post-surgery as previously described (4) (i.e., at GA19.5 or GA21.5, respectively). All fetuses and rats were euthanized using carbon dioxide (30\% volume displaced/min). Death was confirmed using cervical dislocation. A total of three fetal rats were obtained from each pregnant rat, for a total of 54 fetal rats from both GA16.5 and GA18.5 groups, and the survival rate was calculated. Tissue samples from the surgical site on the upper-left lip and asymmetrical sections from the upper-right lip were collected from the fetal rats for histological examination, including hematoxylin and eosin (H\&E) staining, Masson's Trichrome staining and type-I collagen immunohistochemical staining as previously described (14-16).

The upper-left lip tissue samples from the GA16.5 group were defined as group 1, whereas the upper-right lip tissue samples from the GA16.5 group were defined as group 2. In addition, the upper-left lip tissue samples from the GA18.5 group were defined as group 3, whereas the upper-right lip tissue samples from the GA18.5 group were defined as group 4. Each subgroup included 27 samples. Protein expression was compared between group 1 and 2, group 3 and 4, as well as group 3 and 1. Label-free quantification PRM was performed as previously described (17) and was used to detect the differentially expressed proteins among the different groups. MaxQuant 1.5.6 (https://www.maxquant.org) and Perseus 1.4 (https://www.maxquant.org/perseus/) were used to analyze the results of label-free quantification PRM: Volcano plots were generated for differentially expressed proteins: Y-axis, - $\log 10$ (P-value); x-axis: $\log 2$ (ratio). The points distributed outside the two vertical borders and above the horizontal border represented the proteins with significant differences; proteins with at least a 1.5-fold change in expression and $\mathrm{P}<0.05$ were considered significant. Subsequently, bioinformatics analysis, including GO and KEGG pathway analysis, was performed to identify differentially expressed proteins (18).

Experimental verification of tissue repair proteins in fetal rats with artificial cleft lip wounds. The mRNA levels of the differentially expressed molecules were assessed using reverse transcription-quantitative (RT-q) PCR, as previously described (19). Differentially expressed levels of proteins were detected by label-free quantification PRM as previously described (17).

Statistical analysis. GraphPad Prism 8.0 (GraphPad Software, Inc.) and SPSS 22.0 (IBM Corp.) were used to perform calculations and carry out statistical analysis. Student's t-test was used to compare differences between two groups. The experimental data from each group were analyzed for congruence of variance before the t-test were applied. The FDR values were within 0.01 in the comparisons. Mixed ANOVA followed by Sidak's post hoc test was used to analyze the differences between multiple groups. $\mathrm{P}<0.05$ was considered to indicate a statistically significant difference.

\section{Results}

Gross observation. All fetal rats were observed before delivery. The nasolabial cleft was first observed before surgery and images were captured to facilitate the observation of changes in the fetal rats from the GA16.5 and GA18.5 groups. We observed the same area again $72 \mathrm{~h}$ post-surgery to identify differences. The cuneiform tissue of the upper-left lip was removed by microsurgery to create a cleft lip wound. The changes in the fetal rats were observed macroscopically. In the GA16.5 group, the upper-left cleft lip wound completely healed $72 \mathrm{~h}$ after surgery (i.e., GA19.5) and the continuity of the upper lip tissue was restored. Only a slight depression was observed in the surgical area. The upper-left lip tissue was nearly symmetrical with that of the right side. However, in the GA18.5 group, the cleft lip wound was not completely healed $72 \mathrm{~h}$ after surgery (i.e., GA21.5); a clear scar was observed in the surgical area, and the upper lip was asymmetrical on both sides due to wound contracture (Fig. 1). 
A

B

c D

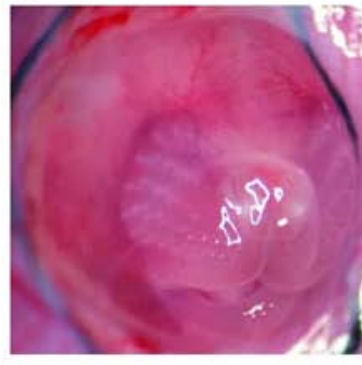

E

F
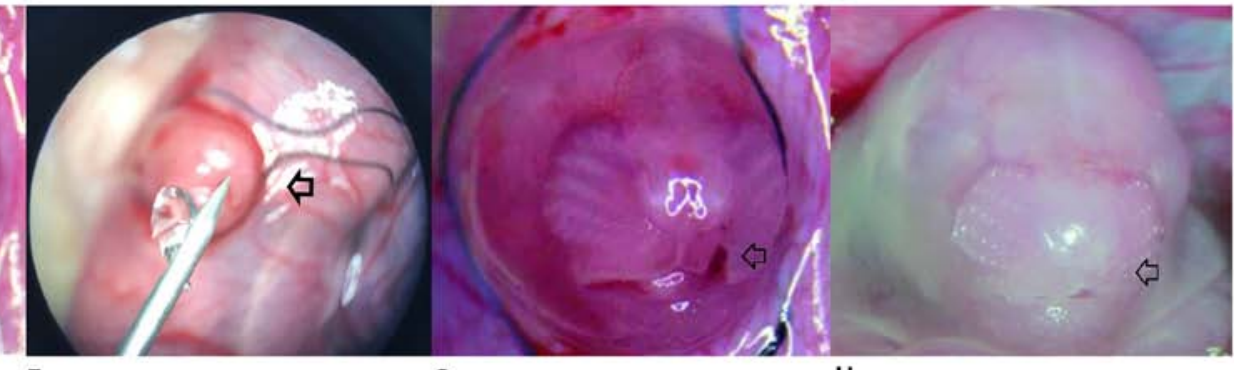

H
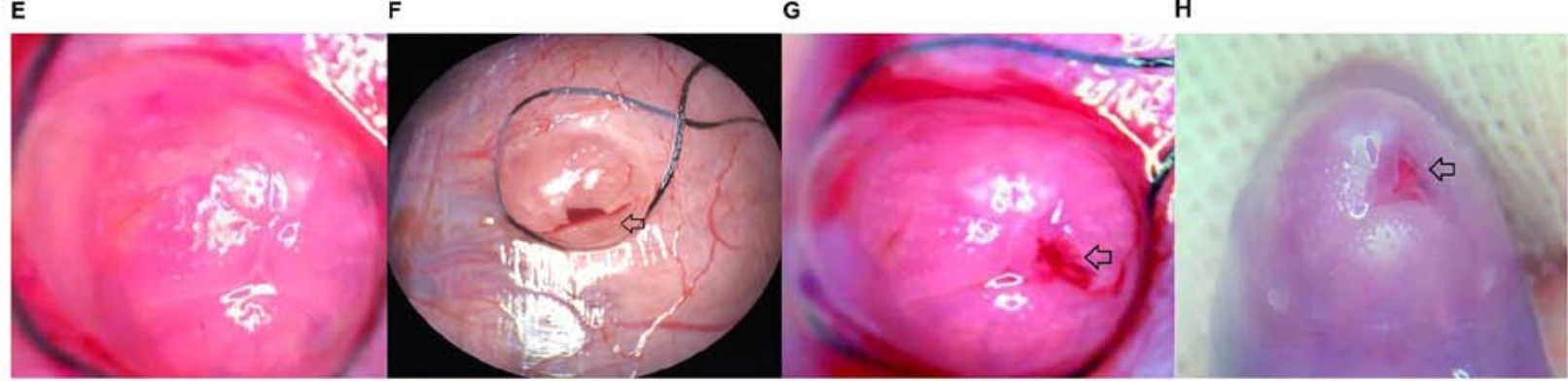

Figure 1. Macroscopic appearance of the cleft lip in the GA16.5 and GA18.5 groups. Arrows indicate the surgical site on the upper-left cleft lip of the fetus. (A-D) Macroscopic appearance of the upper-left lip of a fetus from the GA16.5 group (A) prior to surgery, (B) during surgery, (C) immediately after surgery and (D) $72 \mathrm{~h}$ after surgery. (E-H) Macroscopic appearance of the upper-left lip of a fetus from the GA18.5 group (E) prior to surgery, (F) during surgery, (G) immediately after surgery and (H) $72 \mathrm{~h}$ after surgery. GA, gestational age.
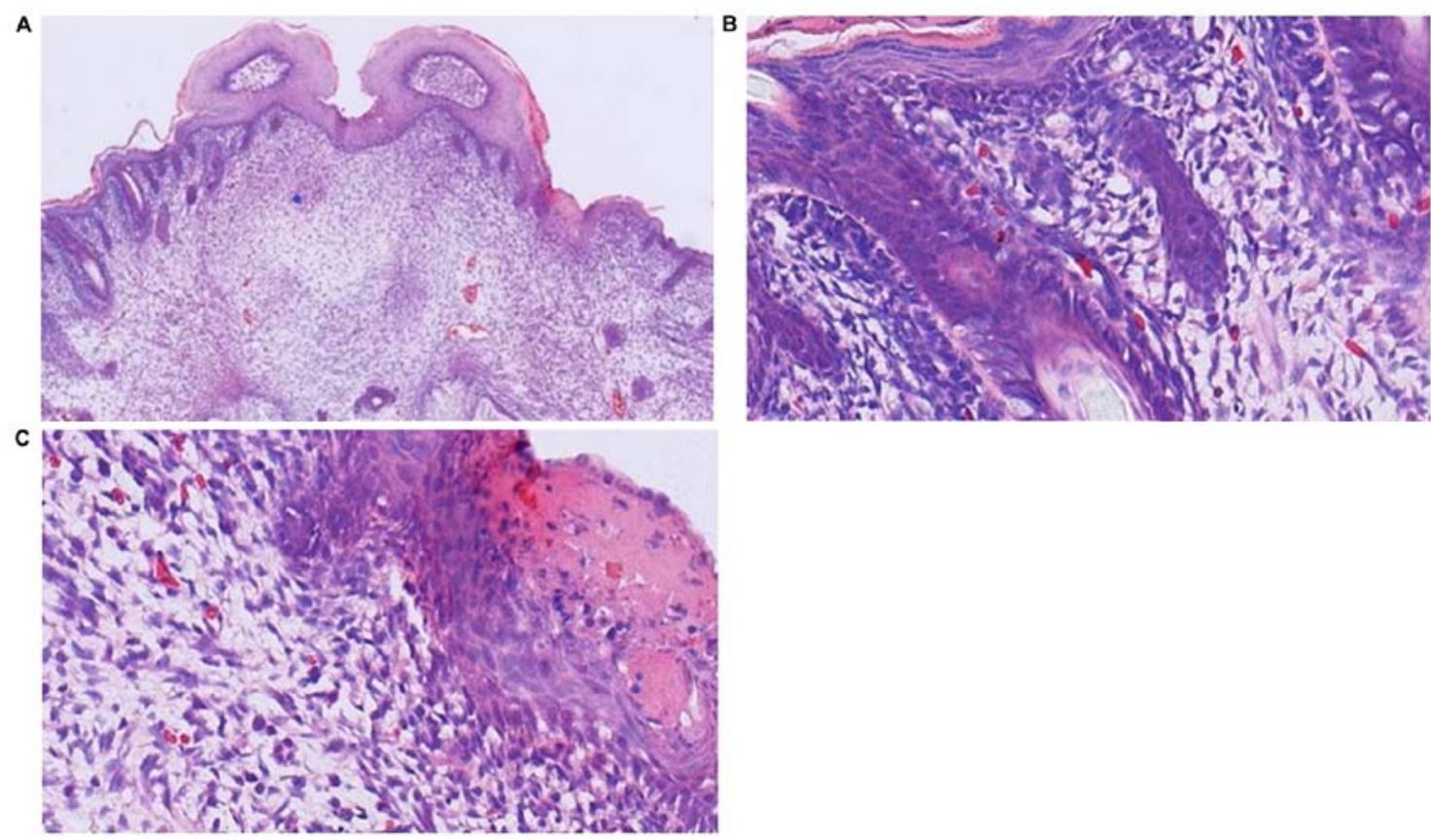

Figure 2. H\&E staining of upper lip tissue $72 \mathrm{~h}$ following model establishment in the GA16.5 group. (A) H\&E staining of the upper lip tissue. The slight depression in the upper-left lip identifies the location where the cleft lip-like defect was created. The site of the defect is completely epithelialized. Magnification, $\mathrm{x} 40$. (B) Normal subepidermal structure of the upper-right lip. Magnification, x400. (C) New follicular structures can be observed under the epidermis of the upper-left lip. Magnification, x400. GA, gestational age; H\&E, hematoxylin and eosin.

Histological analysis. In the GA16.5 group $72 \mathrm{~h}$ after surgery, the tissue of the upper-left lip wound demonstrated complete regeneration when observed under the microscope (Figs. 2-4). The results of H\&E staining demonstrated complete epithelialization of the upper-left lip, and the structure of new follicles was detected under the epidermis. Compared with the normal skin of the upper-right lip, a slight depression in the cleft part of the upper-left lip and thickening of the skin was noted, whereas inflammatory cell infiltration and neovascularization were not apparent (Fig. 2). Masson's Trichrome staining revealed collagen fibers under the epidermis, demonstrating a fine reticular and emerging follicular structure (Fig. 3). Immunohistochemical analysis indicated no obvious difference in the amount of type-I collagen in the upper-left cleft lip area and the rest of the upper lip (Fig. 4). 

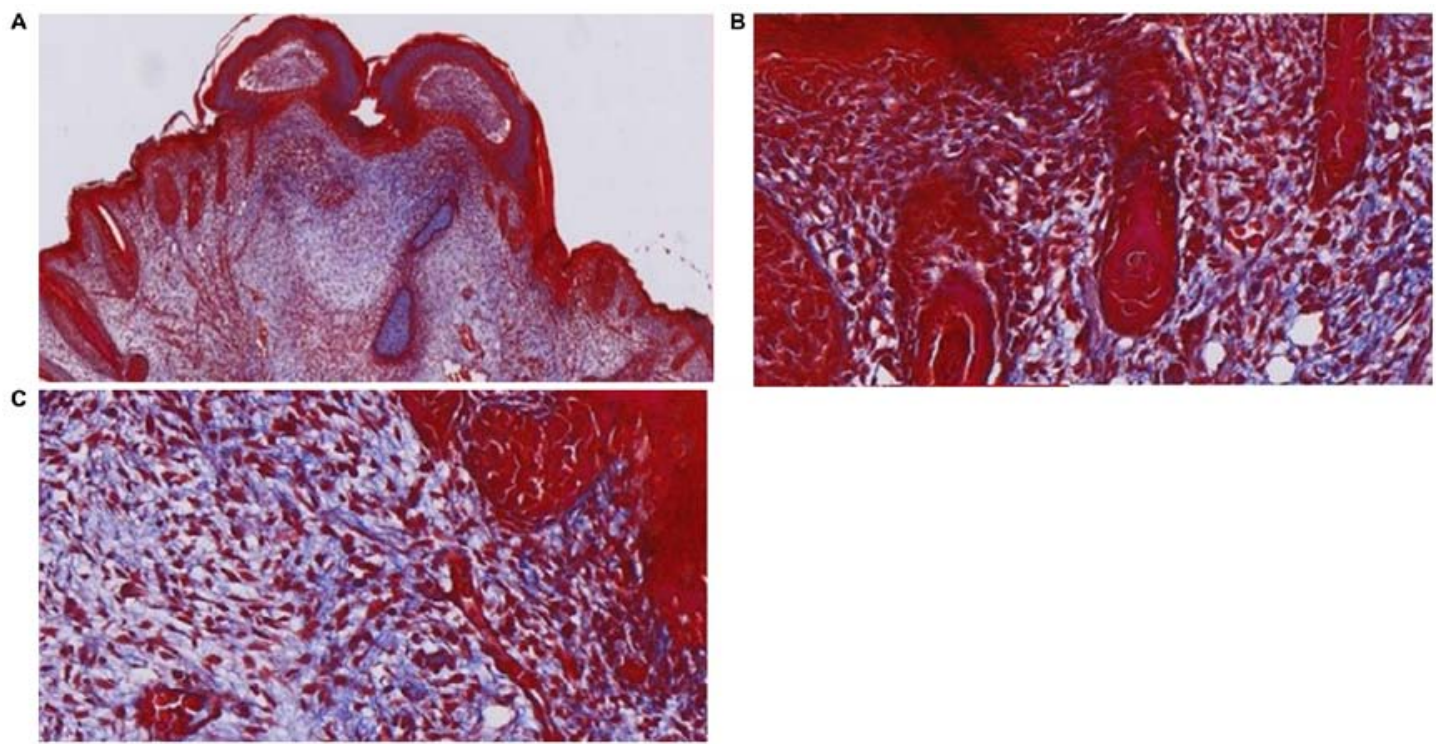

Figure 3. Masson's Trichrome staining $72 \mathrm{~h}$ following model establishment in the GA16.5 group. (A) Masson's Trichrome staining of the upper lip tissue. The slight depression in the upper-left lip identifies the location where the cleft lip-like defect was created. Magnification, x40. (B) Normal subepidermal structure of the upper-right lip. Magnification, $\mathrm{x} 400$. (C) The fine network of collagen fibers (stained blue) and new hair follicle structures are visible under the epidermis of the upper-left lip. Magnification, x400. GA, gestational age.
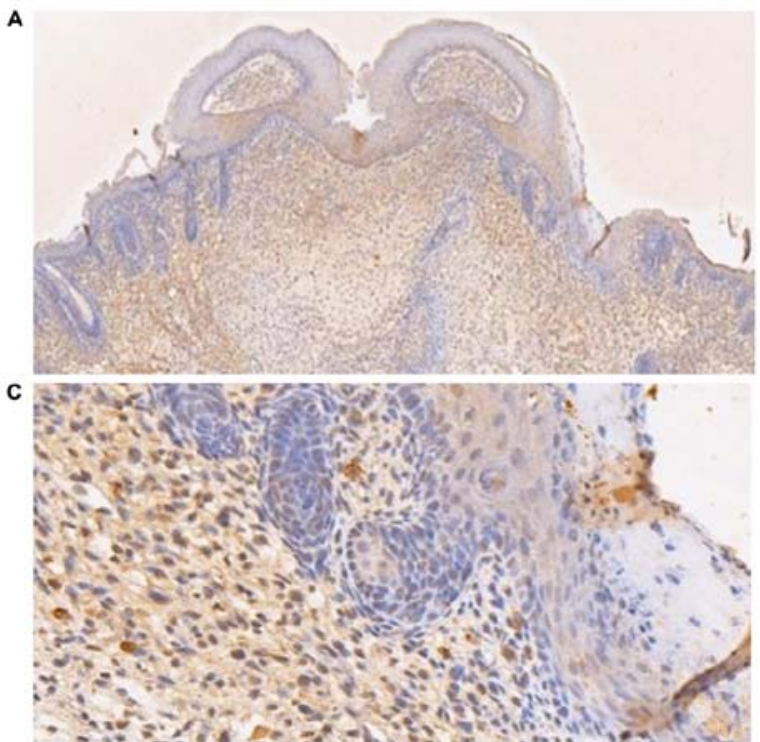

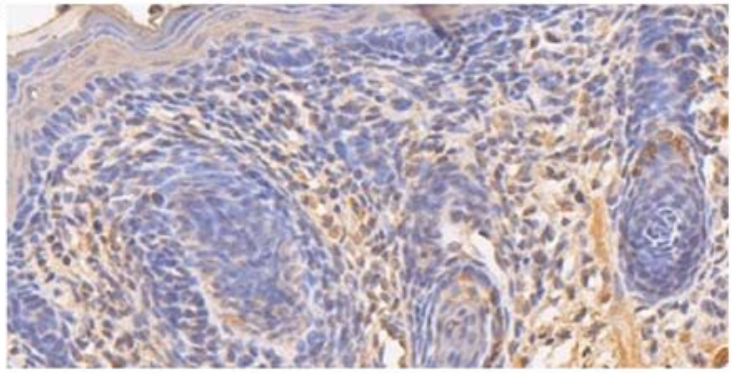

Figure 4. IHC staining $72 \mathrm{~h}$ following model establishment in the GA16.5 group. (A) IHC staining of the upper lip tissue. The slight depression in the upper-left lip identifies the location where the cleft lip-like defect was created. Magnification, x40. (B) Normal subepidermal structure of the upper-right lip. Magnification, $\mathrm{x}$ 400. (C) The expression of type-I collagen in the upper-left lip is almost indistinguishable from the upper-right lip. Magnification, $\mathrm{x} 400$. GA, gestational age; IHC, immunohistochemistry.

In the GA18.5 group, the position of the wound was easily identified by a distinct scar on the upper-left lip. H\&E staining demonstrated that partial epithelialization occurred in the upper-left cleft lip area. Compared with the normal skin of the upper-right lip, the upper-left lip displayed a clear scar, new capillary formation around the wound and increased fibroblast proliferation and ECM volume, whereas structural components of hair follicles were not observed under the epidermis (Fig. 5). Masson's Trichrome staining demonstrated the absence of new follicular structure and the presence of dense collagen fibers under the epidermis (Fig. 6). Immunohistochemical analysis in the upper-left cleft lip wound demonstrated an increase in type-I collagen expression and fiber density, as well as a more compact structure and absence of adnexal skin (Fig. 7), compared with normal upper lip tissue.

Immunohistochemical analysis of cell proliferation markers was also carried out. Compared with GA16.5 fetal rats, the expression of Ki67 and CD31 slightly increased in the GA18.5 group following surgery. By contrast, the expression of CK10 decreased in the GA18.5 group, compared with the GA16.5 group (Fig. 8).

$R T-q P C R$ analysis of inflammatory factors. The relative mRNA expression levels of the pro-inflammatory factors 

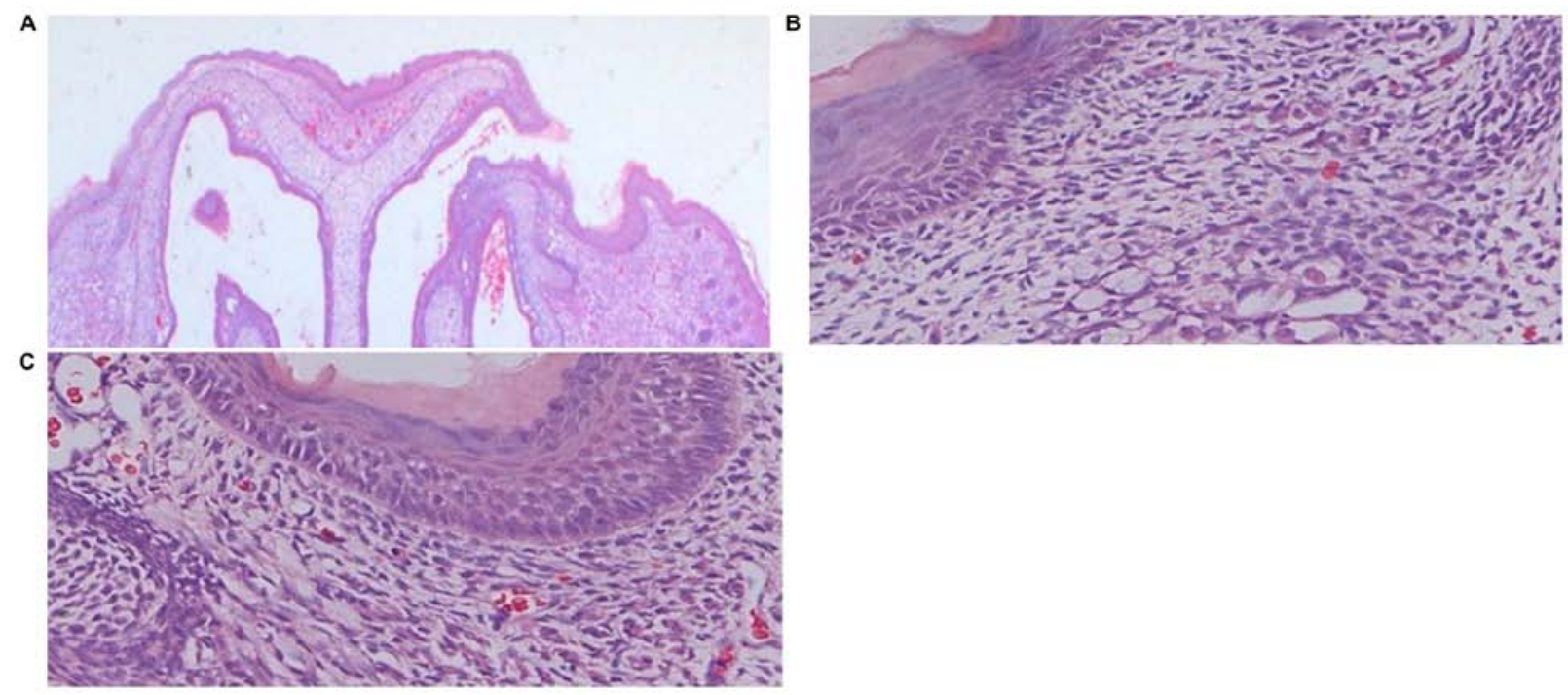

Figure 5. H\&E staining of upper lip tissue $72 \mathrm{~h}$ following model establishment in the GA18.5 group. (A) H\&E staining of the upper lip tissue. A clear depression in the upper-left lip identifies the location where the cleft lip-like defect was created. The site of the defect is not completely healed. Magnification, $\mathrm{x} 40$ (B) Normal subepidermal structure of the upper-right lip. Magnification, $\mathrm{x} 400$. (C) No new hair follicle structures were observed under the epidermis. New capillaries, an increased number of fibroblasts and an increased volume of extracellular matrix can be observed around the wound. Magnification, x400. GA, gestational age.
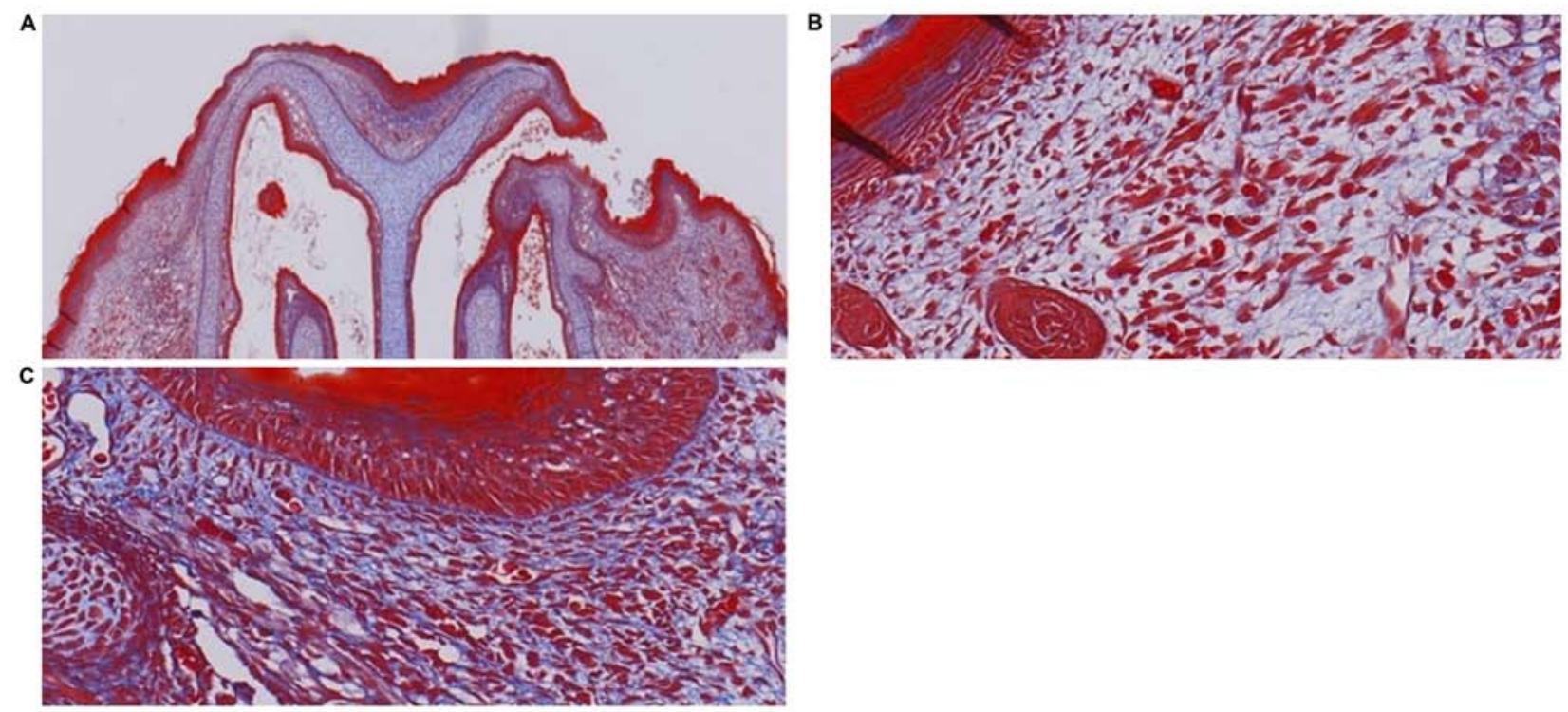

Figure 6. Masson's Trichrome staining $72 \mathrm{~h}$ after model establishment in the GA18.5 group. (A) Masson's Trichrome staining of the upper lip tissue. A clear depression in the upper-left lip identifies the location where the cleft lip-like defect was created Magnification, x40. (B) Normal subepidermal structure of the upper-right lip. Magnification, x400. (C) The collagen fibers (stained blue) are visible and no new hair follicle structures are observed under the epidermis of the upper-left lip. Magnification, $\mathrm{x} 400$. GA, gestational age.

TNF- $\alpha$, IL-10 and TGF- $\beta$ were evaluated in the two groups of fetal rats. The mRNA levels of TNF- $\alpha$ and IL-10 were significantly higher in GA18.5 rats, compared with GA16.5 rats. Furthermore, the mRNA expression levels of TGF- $\beta$ were significantly reduced in the GA18.5 group (Fig. 9).

Protein identification and differential protein screening. Compared with group 1, 57 differentially expressed proteins were identified in group 2, of which 37 were upregulated and 20 were downregulated. A comparison of groups 3 and 4 revealed 312 differentially expressed proteins, of which 171 were upregulated and 141 were downregulated. Lastly, compared with group 1,289 differentially expressed proteins were identified in group 3, of which 151 were upregulated and 138 were downregulated. Only 50 differentially expressed proteins and their multiple variations were upregulated or downregulated between all groups (Tables I-IV). The distribution of the differentially expressed proteins among the selected samples is presented as volcano plots (Figs. 10-12).

Bioinformatics analysis. Gene ontology (GO) enrichment analysis was performed on the differentially expressed proteins, and their properties were generally described as 

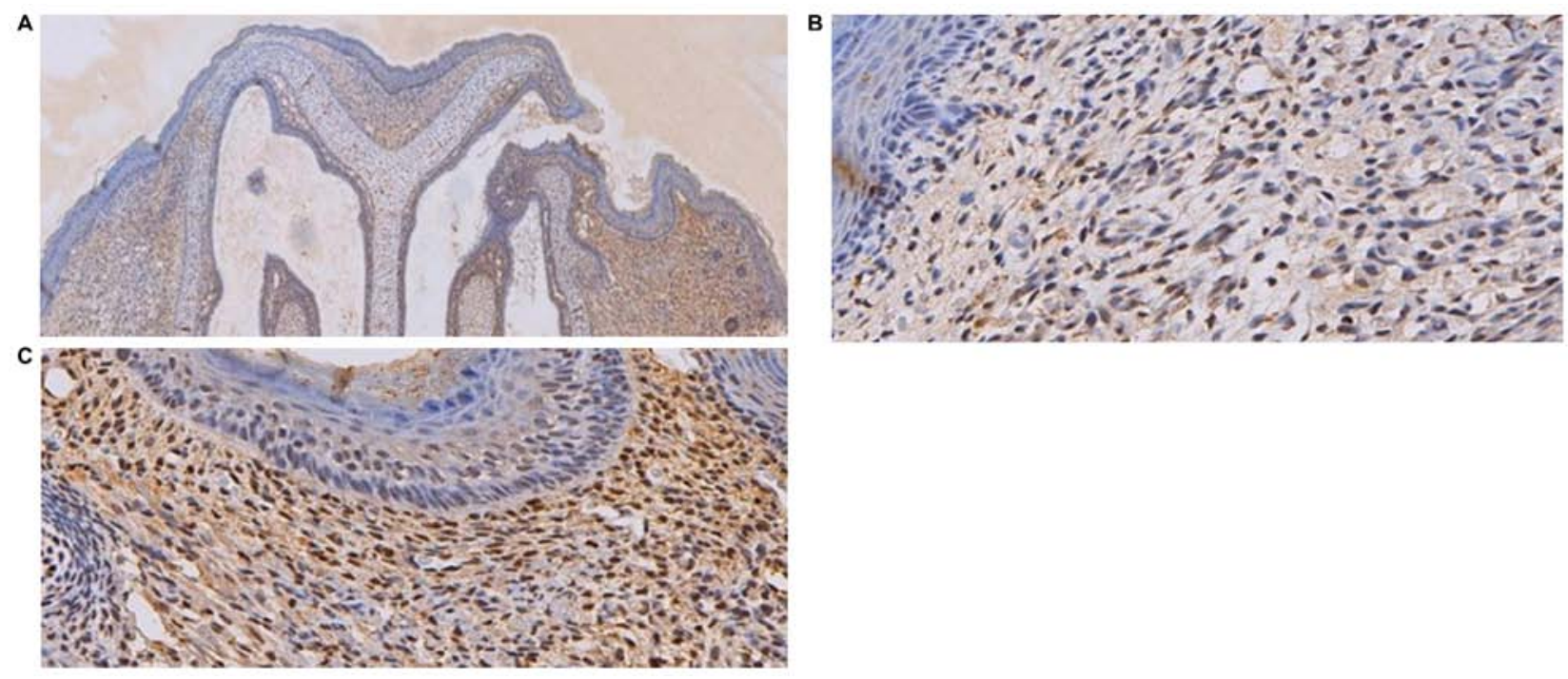

Figure 7. IHC staining $72 \mathrm{~h}$ after model establishment in the GA18.5 group. (A) IHC staining of the upper lip tissue. A clear depression in the upper-left lip identifies the location where the cleft lip-like defect was created Magnification, $x 40$. (B) Normal subepidermal structure of the upper-right lip. Magnification, x400. (C) The expression of type-I collagen in the upper-left lip is higher compared with the upper-right lip. Magnification, x400. GA, gestational age; IHC, immunohistochemistry.
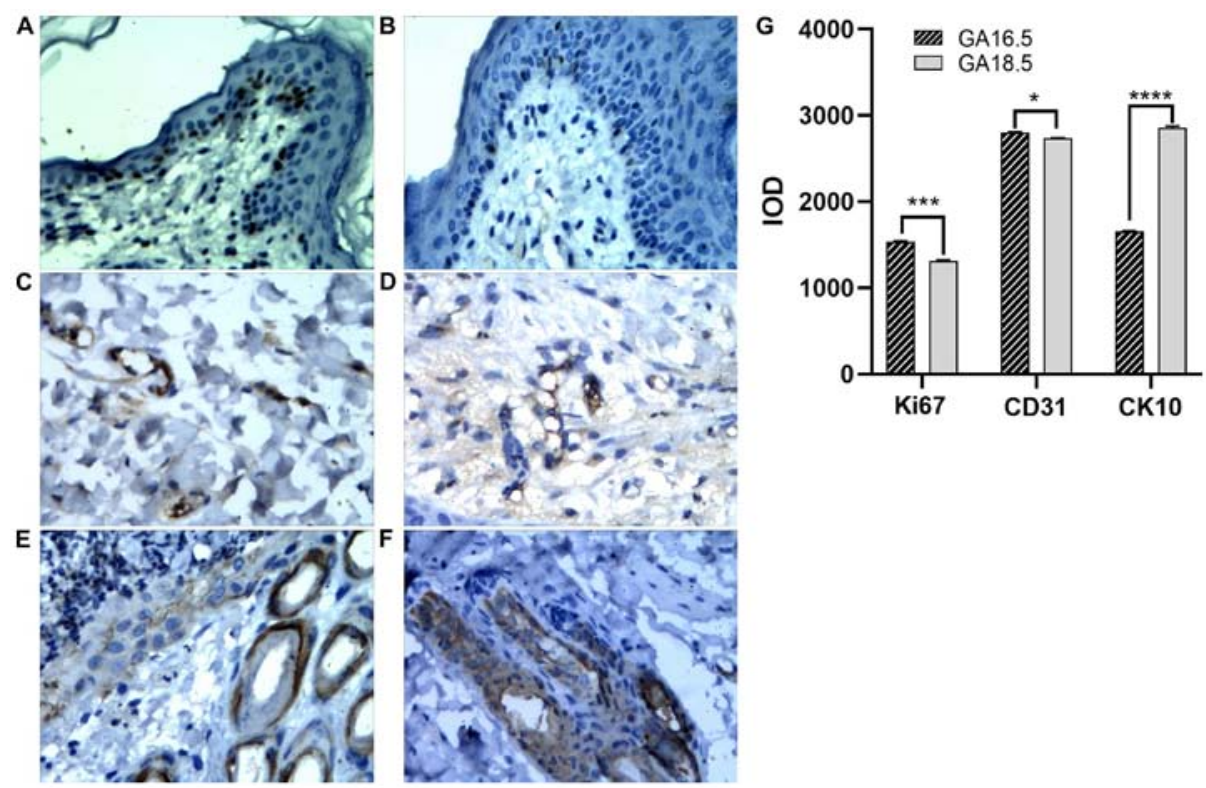

Figure 8. Immunohistochemical analysis $72 \mathrm{~h}$ after model establishment in the GA16.5 and GA18.5 groups. (A and B) Ki67 staining of upper lip tissue from (A) the GA16.5 group and (B) the GA18.5 group. (C and D) CD31staining of upper lip tissue from (C) the GA16.5 group and (D) the GA18.5 group. (E and F) CK10 staining of upper lip tissue from (E) the GA16.5 group and (F) the GA18.5 group. (G) IOD values for Ki67, CD31 and CK10 staining in both groups. ${ }^{*} \mathrm{P}<0.05 ;{ }^{* * *} \mathrm{P}<0.001 ;{ }^{* * * *} \mathrm{P}<0.0001$. GA, gestational age; IOD, integral optical density.

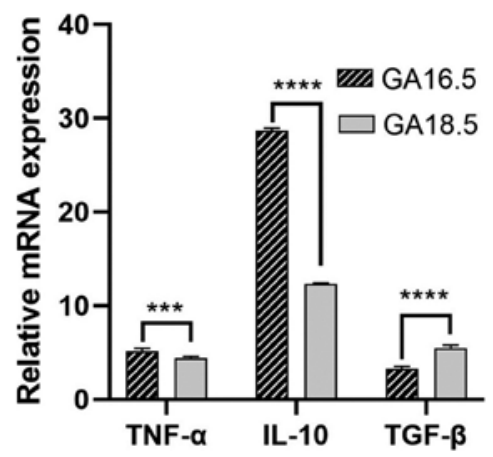

Figure 9. Relative mRNA expression levels of TNF- $\alpha$, IL-10 and TGF- $\beta$. ${ }^{* * * * *} \mathrm{P}<0.001 ;{ }^{* * * * *} \mathrm{P}<0.0001$. GA, gestational age. biological process (BP), molecular function (MF) or cellular component (CC). The first $10 \mathrm{GO}$ enrichment results from each group are displayed in Fig. 13. The results demonstrated that 73,542 and 376 differentially expressed proteins were significantly enriched between groups 1 and 2, 3 and 4 and 3 and 1, respectively. The results of the Kyoto Encyclopedia of Genes and Genomes (KEGG) pathway enrichment analysis identified the possible pathway related to the differentially expressed proteins between groups (Fig. 14).

In addition, the interaction network of the differentially expressed proteins that regulate wound repair were analyzed. Examples of the interaction networks of the differentially expressed proteins involved in wound repair are as follows: 
Table I. Comparison of differentially expressed protein numbers between samples.

\begin{tabular}{lccr}
\hline Sample & Differentially expressed proteins, $\mathrm{n}$ & Upregulated proteins, $\mathrm{n}$ & Downregulated protein, $\mathrm{n}$ \\
\hline Group 1 vs. Group 2 & 57 & 37 & 20 \\
Group 3 vs. Group 4 & 312 & 171 & 141 \\
Group 3 vs. Group 1 & 312 & 151 \\
\hline Group 1, upper-left lip without scar repair group at 72 h after modeling in GA16.5 rats; Group 2, upper-right lip normal group at 72 h after \\
modeling in GA16.5 rats; Group 3, upper-left lip scar repair group at 72 h after modeling in GA18.5 rats; Group 4, upper-right lip normal group \\
at 72 h after modeling in GA18.5 rats.
\end{tabular}

Table II. Differential protein expression in group 1 and group 2.

\begin{tabular}{|c|c|c|c|c|}
\hline Protein ID & Gene name & Protein name & P-value & Fold-change \\
\hline G3V8R3 & $\mathrm{Hbz}$ & Hemoglobin, zeta & 0.004 & 7.788 \\
\hline B2RYS8 & Ndufb8 & NADH dehydrogenase & 0.000 & 5.024 \\
\hline Q920P6 & Ada & Adenosine deaminase & 0.038 & 4.831 \\
\hline O88752 & Hbe 1 & Hemoglobin, epsilon 1 & 0.003 & 4.801 \\
\hline Q499N7 & Ptpn6 & Tyrosine-protein phosphatase non-receptor type 6 & 0.003 & 4.700 \\
\hline Q4FZU2 & Krt6a & Keratin 6A & 0.001 & 4.044 \\
\hline P06762 & Hmox 1 & Heme oxygenase 1 & 0.011 & 3.902 \\
\hline Q6IFU9 & Krt16 & Keratin, type I cytoskeletal 16 & 0.006 & 3.613 \\
\hline Q99PD6 & Tgfb1i1 & Transforming growth factor beta-1-induced transcript 1 protein & 0.004 & 3.590 \\
\hline Q6P7S1 & Asah1 & Acid ceramidase & 0.029 & 3.167 \\
\hline Q63066 & Hbg 1 & Hemoglobin, gamma A & 0.002 & 3.082 \\
\hline Q10758 & Krt8 & Keratin, type II cytoskeletal 8 & 0.004 & 2.901 \\
\hline Q6AYQ4 & Tmem109 & Transmembrane protein 109 & 0.048 & 2.710 \\
\hline Q9Z2Q7 & Stx8 & Syntaxin-8 & 0.035 & 2.660 \\
\hline G3V9M8 & Fam50a & Protein fam50a & 0.034 & 2.515 \\
\hline M0R9Y3 & Nup43 & Nucleoporin 43 & 0.005 & 2.461 \\
\hline B2GVB9 & Fermt3 & Fermitin family homolog 3 & 0.018 & 2.425 \\
\hline G3V8H & Olfml3 & Olfactomedin-like protein 3 precursor & 0.045 & 2.383 \\
\hline D4A531 & Polr2i & Rna polymerase ii subunit i & 0.049 & 2.290 \\
\hline Q68FS1 & Nubp2 & Cytosolic Fe-S cluster assembly factor & 0.028 & 2.221 \\
\hline D3ZLS5 & Hectd 1 & Hect domain e3 ubiquitin protein ligase 1 & 0.033 & 2.112 \\
\hline D4A0M2 & Nxn & Nucleoredoxin & 0.033 & 2.056 \\
\hline Q6IE17 & Stfa212 & Stefin-3 & 0.007 & 1.969 \\
\hline P27139 & $\mathrm{Ca} 2$ & Carbonic anhydrase 2 & 0.032 & 1.957 \\
\hline D3ZF44 & LOC684499 & Protein LOC684499 & 0.015 & 1.940 \\
\hline Q6LDZ3 & Ptprc & Receptor-type tyrosine-protein phosphatase C & 0.007 & 1.878 \\
\hline Q5XI38 & Lcp1 & Plastin-2 & 0.018 & 1.843 \\
\hline Q5PPG2 & Lgmn & Legumain precursor & 0.015 & 1.820 \\
\hline P06765 & Pf4 & Platelet factor 4 & 0.050 & 1.708 \\
\hline Q9R1T3 & Ctsz & Cathepsin Z & 0.011 & 1.707 \\
\hline Q5U1Y2 & Rac2 & Ras-related $\mathrm{C} 3$ botulinum toxin substrate 2 & 0.021 & 1.669 \\
\hline Q5U2V4 & Plbd1 & Phospholipase B-like 1 & 0.028 & 1.630 \\
\hline Q9EPX0 & Hspb8 & Heat shock protein beta- 8 & 0.005 & 1.603 \\
\hline O35532 & Msmo1 & Methylsterol monooxygenase 1 & 0.037 & 1.592 \\
\hline Q91ZN1 & Corola & Coronin-1A & 0.013 & 1.586 \\
\hline O88201 & Clec11a & C-type lectin domain family 11 member A & 0.025 & 1.547 \\
\hline Q5U329 & Slc4a1 & Band 3 anion transport protein & 0.027 & 1.512 \\
\hline Q496Z5 & Prph & Peripherin & 0.041 & 0.626 \\
\hline P19527 & Nefl & Neurofilament light polypeptide & 0.040 & 0.608 \\
\hline
\end{tabular}


Table II. Continued.

\begin{tabular}{|c|c|c|c|c|}
\hline Protein ID & Gene name & Protein name & P-value & Fold-change \\
\hline Q9ESI7 & Dcx & Neuronal migration protein doublecortin & 0.003 & 0.597 \\
\hline Q6AY98 & Ube2e2 & Ubiquitin conjugating enzyme e 2 e 2 & 0.046 & 0.577 \\
\hline Q7TSX7 & $\mathrm{Nr} 3 \mathrm{c} 1 ; \mathrm{gr}$ & Glucocorticoid receptor & 0.026 & 0.560 \\
\hline O70437 & Smad4 & Mothers against decapentaplegic homolog 4 & 0.043 & 0.557 \\
\hline F1M754 & Map4k4 & Mitogen-activated protein kinase kinase kinase kinase 4 & 0.022 & 0.526 \\
\hline D4A2Z8 & Dhx36 & Probable ATP-dependent RNA helicase DHX36 & 0.009 & 0.522 \\
\hline P31430 & Dpep1 & Dipeptidase 1 & 0.010 & 0.513 \\
\hline Q6AXY8 & Dhrs1 & Dehydrogenase/reductase SDR family member 1 & 0.019 & 0.495 \\
\hline D4A414 & Cox 15 & COX15 homolog & 0.031 & 0.476 \\
\hline D4ABV5 & Calm1 & Calmodulin 1 & 0.012 & 0.473 \\
\hline D3ZRN3 & Actbl2 & Beta-actin-like protein 2 & 0.048 & 0.413 \\
\hline Q8CGS4 & Chmp3 & Charged multivesicular body protein 3 & 0.022 & 0.410 \\
\hline D3ZHA7 & Myl6b & Myosin light chain $6 b$ & 0.011 & 0.390 \\
\hline P70541 & Eif2b3 & Translation initiation factor eif-2B subunit gamma & 0.002 & 0.324 \\
\hline D3ZX50 & Krtap11-1 & Uncharacterized protein & 0.037 & 0.287 \\
\hline D3ZD07 & Fmo9 & Flavin containing monooxygenase 9 pseudogene & 0.007 & 0.277 \\
\hline Q6IFX1 & Krt24 & Keratin, type I cytoskeletal 24 & 0.012 & 0.050 \\
\hline Q6IG02 & Krt2 & Keratin, type II cytoskeletal 2 & 0.008 & 0.021 \\
\hline
\end{tabular}

Group 1: Upper-left lip of fetus at $72 \mathrm{~h}$ after modeling in GA16.5 rats; Group 2, upper-right lip of fetus at $72 \mathrm{~h}$ after modeling in GA16.5 rats. GA, gestational age.

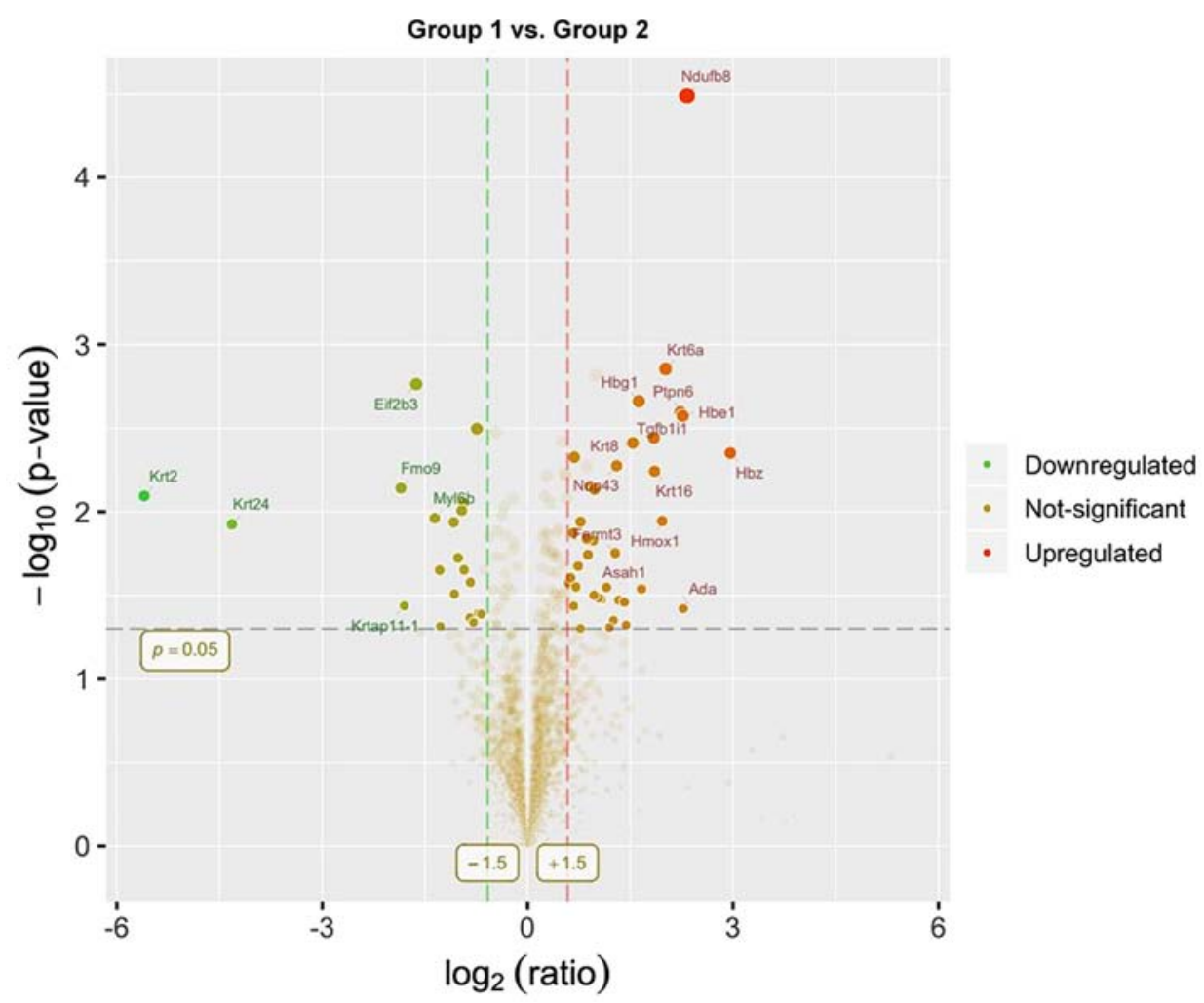

Figure 10. Volcano plot of the differentially expressed proteins in group 1 and group 2. Group 1, upper-left lip of fetus at $72 \mathrm{~h}$ after modeling in GA16.5 rats; Group 2, upper-right lip of fetus at $72 \mathrm{~h}$ after modeling in GA16.5 rats. GA, gestational age.

i) Smad4, Tgf1i1, Ptpn6 and Hmox1 in group 1 and 2; and iii) CD36, S100a9, S100a8, Cd9Fgg, Anxa1, Fgb, Plg and ii) S100a9, Fgg, Anxa1, Fgb, Plg and S100a8 in group 3 and 4; S100a8 in group 3 and 1 (Fig. 15). 
Table III. Differential protein expression in group 3 and group 4.

\begin{tabular}{|c|c|c|c|c|}
\hline Protein ID & Gene name & Protein name & P-value & Fold change \\
\hline D3ZGE2 & Mpo & Myeloperoxidase & 0.000 & 377.923 \\
\hline Q62714 & $\mathrm{Np} 4$ & Neutrophil antibiotic peptide NP-4 & 0.000 & 231.771 \\
\hline D3ZY96 & Ngp & Neutrophilic granule protein precursor & 0.010 & 226.724 \\
\hline P50115 & S100a8 & S100 Calcium Binding Protein A8 & 0.001 & 92.828 \\
\hline Q7TP54 & Fam65b & Protein FAM65B & 0.000 & 77.718 \\
\hline D3ZMI6 & Olfm4 & Olfactomedin-4 precursor & 0.001 & 63.833 \\
\hline D4A081 & Setdb1 & Histone-lysine N-methyltransferase SETDB1 & 0.000 & 47.032 \\
\hline Q9JI30 & Itgam & Integrin alpha-M precursor & 0.011 & 39.489 \\
\hline B2RYB8 & Itgb2 & Integrin beta 2 precursor & 0.003 & 34.443 \\
\hline P50116 & S100a9 & S100 Calcium Binding Protein A9 & 0.000 & 30.191 \\
\hline Q920P6 & Ada & Adenosine deaminase & 0.028 & 27.433 \\
\hline Q499N7 & Ptpn6 & Tyrosine-protein phosphatase non-receptor type 6 & 0.003 & 23.157 \\
\hline Q9ERL1 & Cybb & Cytochrome b-245, beta polypeptide & 0.002 & 21.484 \\
\hline Q9JKB7 & Gda & Guanine deaminase & 0.019 & 20.202 \\
\hline Q5U1Y2 & Rac2 & Ras-related $\mathrm{C} 3$ botulinum toxin substrate 2 & 0.007 & 19.291 \\
\hline Q6IFU9 & Krt16 & Keratin, type I cytoskeletal 16 & 0.001 & 13.524 \\
\hline O54854 & Klk6 & Kallikrein-6 precursor & 0.000 & 11.605 \\
\hline B2GVB9 & Fermt3 & Fermitin family homolog 3 & 0.012 & 11.176 \\
\hline Q5PQW8 & Gbp2 & Interferon-induced guanylate-binding protein 2 & 0.019 & 10.854 \\
\hline Q6LDZ3 & Ptprc & Receptor-type tyrosine-protein phosphatase C & 0.015 & 10.626 \\
\hline Q4G075 & Serpinb1a & Leukocyte elastase inhibitor A & 0.001 & 9.051 \\
\hline Q6PDV1 & Lyz1 & Lysozyme C-1 precursor & 0.002 & 9.049 \\
\hline Q6IE17 & Stfa212 & Stefin-3 & 0.000 & 8.930 \\
\hline Q5U2V4 & Plbd1 & Phospholipase B-like 1 & 0.003 & 8.669 \\
\hline Q91ZN1 & Corola & Coronin-1A & 0.001 & 8.199 \\
\hline P14669 & Anxa3 & Annexin A3 & 0.008 & 8.100 \\
\hline Q9R0D6 & $\operatorname{Tcn} 2$ & Transcobalamin-2 precursor & 0.014 & 7.286 \\
\hline Q4QQV6 & Lsp1 & Lymphocyte specific 1 & 0.004 & 6.785 \\
\hline P06768 & Rbp2 & Retinol-binding protein 2 & 0.006 & 6.051 \\
\hline Q5XI38 & Lcp1 & Plastin-2 & 0.001 & 5.841 \\
\hline Q91W30 & Akr1b8 & Aldo-Keto Reductase Family 1 Member B8 & 0.001 & 5.492 \\
\hline Q63015 & Csap1 & Common salivary protein 1 precursor & 0.001 & 5.454 \\
\hline P31720 & C1qa & Complement $\mathrm{C} 1 \mathrm{q}$ subcomponent subunit $\mathrm{A}$ & 0.008 & 5.339 \\
\hline G3V904 & Pld4 & Phospholipase D4 & 0.005 & 4.857 \\
\hline D4ADD7 & Glrx5 & Glutaredoxin-related protein 5 & 0.002 & 4.782 \\
\hline P22985 & Xdh & Xanthine dehydrogenase/oxidase & 0.003 & 4.221 \\
\hline P06866 & Hp & Haptoglobin Haptoglobin alpha chain Haptoglobin beta chain & 0.002 & 3.945 \\
\hline B2RYS9 & Trmt112 & Uncharacterized protein & 0.016 & 3.827 \\
\hline $\mathrm{P} 23640$ & Rab27a & Ras-related protein Rab-27A & 0.017 & 3.774 \\
\hline P06762 & Hmox 1 & Heme oxygenase 1 & 0.008 & 3.769 \\
\hline Q9WUQ4 & Slpi & Secretory leukocyte peptidase inhibitor precursor & 0.015 & 3.710 \\
\hline P07150 & Anxa1 & Annexin A1 & 0.003 & 3.449 \\
\hline D3ZX79 & Ly6g6c & Lymphocyte antigen 6 complex G6C precursor & 0.018 & 3.236 \\
\hline O88752 & Hbe 1 & Hemoglobin, epsilon 1 & 0.029 & 3.211 \\
\hline Q9R1T3 & Ctsz & Cathepsin Z & 0.002 & 3.195 \\
\hline D3ZJH9 & $\mathrm{Me} 2$ & NAD-dependent malic enzyme, mitochondrial & 0.034 & 2.926 \\
\hline P05942 & S100a4 & S100 Calcium Binding Protein A4 & 0.002 & 2.897 \\
\hline Q5XJW6 & Cfh & Complement factor $\mathrm{H}$ precursor & 0.008 & 2.891 \\
\hline O54892 & $\mathrm{Hk} 2$ & Hexokinase- 2 & 0.007 & 2.876 \\
\hline Q6P7D4 & Cyp20a1 & Cytochrome P450 20A1 & 0.013 & 0.490 \\
\hline D3ZWC6 & Sntb1 & beta-1-syntrophin & 0.025 & 0.490 \\
\hline Q62997 & Gfra1 & GDNF family receptor alpha-1 & 0.043 & 0.488 \\
\hline
\end{tabular}


Table III. Continued.

\begin{tabular}{|c|c|c|c|c|}
\hline Protein ID & Gene name & Protein name & P-value & Fold change \\
\hline P02600 & Myl1 & Myosin light chain $1 / 3$ & 0.011 & 0.482 \\
\hline O35878 & Hspb2 & Heat shock protein beta- 2 & 0.005 & 0.481 \\
\hline P17209 & Myl4 & Myosin light chain 4 & 0.004 & 0.475 \\
\hline D4A8H3 & Uba6 & Ubiquitin-like modifier-activating enzyme 6 & 0.031 & 0.471 \\
\hline A1L1K3 & Anapc5 & Anaphase-promoting complex subunit 5 & 0.046 & 0.470 \\
\hline D3ZTW9 & Exog & Nuclease EXOG & 0.028 & 0.467 \\
\hline D4A3D2 & Smyd1 & SET and MYND domain-containing protein 1 & 0.004 & 0.465 \\
\hline P04466 & Mylpf & Myosin regulatory light chain 2 & 0.009 & 0.464 \\
\hline P12847 & Myh3 & Myosin-3 & 0.007 & 0.461 \\
\hline P13413 & Tnni1 & Troponin I & 0.001 & 0.460 \\
\hline D4A4Y2 & Hsd17b14 & 17-beta-hydroxysteroid dehydrogenase 14 & 0.033 & 0.455 \\
\hline P23928 & Cryab & Alpha-crystallin B chain & 0.020 & 0.454 \\
\hline Q7TNB2 & Tnnt1 & Troponin $\mathrm{T}$ & 0.002 & 0.451 \\
\hline D3ZCD7 & Tp53rk & TP53-regulating kinase & 0.004 & 0.450 \\
\hline P00564 & $\mathrm{Ckm}$ & Creatine kinase M-type & 0.037 & 0.450 \\
\hline Q80W59 & Hrc & $\begin{array}{l}\text { Sarcoplasmic reticulum histidine-rich calcium-binding } \\
\text { protein precursor }\end{array}$ & 0.019 & 0.445 \\
\hline P50463 & Csrp3 & Cysteine and glycine-rich protein 3 & 0.013 & 0.444 \\
\hline Q5XIG1 & Ldb3 & Ldb3 protein & 0.017 & 0.443 \\
\hline D3ZUB7 & Anapc4 & Anaphase-promoting complex subunit 4 & 0.030 & 0.442 \\
\hline Q64578 & Atp2a1 & ATPase, $\mathrm{Ca}++$ transporting, cardiac muscle, fast twitch 1 & 0.032 & 0.442 \\
\hline Q6P792 & Fhl1 & Four and a half LIM domains protein 1 & 0.013 & 0.431 \\
\hline Q8K4F2 & Alox $15 b$ & Arachidonate 15-lipoxygenase B & 0.025 & 0.428 \\
\hline M0RBL8 & Tceal6 & Protein LOC679974 & 0.003 & 0.427 \\
\hline P51868 & Casq2 & Calsequestrin-2 precursor & 0.008 & 0.425 \\
\hline B4F789 & Apobec 2 & Probable C->U-editing enzyme APOBEC-2 & 0.008 & 0.421 \\
\hline P16290 & Pgam2 & Phosphoglycerate mutase 2 & 0.014 & 0.418 \\
\hline Q972J4 & Nexn & Nexilin & 0.002 & 0.412 \\
\hline Q9QYU4 & Crym & Thiomorpholine-carboxylate dehydrogenase & 0.017 & 0.411 \\
\hline D3ZUQ0 & Rilpl1 & RILP-like protein 1 & 0.006 & 0.409 \\
\hline D4A2H6 & Rbfox 3 & Fox-1 homolog C & 0.037 & 0.408 \\
\hline D3ZVM5 & Hspa12b & Heat shock $70 \mathrm{kDa}$ protein $12 \mathrm{~B}$ & 0.038 & 0.406 \\
\hline O54747 & Pold1 & DNA polymerase delta catalytic subunit & 0.001 & 0.403 \\
\hline P52481 & Cap2 & Adenylyl cyclase-associated protein 2 & 0.007 & 0.396 \\
\hline Q63544 & Sncg & Gamma-synuclein & 0.004 & 0.381 \\
\hline Q496Z5 & Prph & Peripherin & 0.001 & 0.376 \\
\hline P07483 & Fabp3 & Fatty acid-binding protein, heart & 0.011 & 0.357 \\
\hline $\mathrm{P} 23565$ & Ina & Alpha-internexin & 0.005 & 0.332 \\
\hline D4ADS4 & Mgst3 & Microsomal glutathione S-transferase 3 & 0.024 & 0.328 \\
\hline P19527 & Nefl & Neurofilament light polypeptide & 0.006 & 0.326 \\
\hline P12839 & Nefm & Neurofilament medium polypeptide & 0.004 & 0.326 \\
\hline B2RZ77 & Dpt & Dermatopontin precursor & 0.024 & 0.320 \\
\hline Q6AYG3 & Prune & Prune homolog & 0.017 & 0.320 \\
\hline G3V7K1 & Myom2 & Myomesin 2 & 0.025 & 0.299 \\
\hline G3V6V5 & Atp1b4 & Protein ATP1B4 & 0.005 & 0.272 \\
\hline Q9Z2Z8 & Dhcr7 & 7-dehydrocholesterol reductase & 0.000 & 0.270 \\
\hline P19633 & Casq1 & Calsequestrin-1 & 0.021 & 0.201 \\
\hline D3ZX18 & Myoz2 & Myozenin-2 & 0.001 & 0.198 \\
\hline Q812D3 & Ppil3 & Peptidyl-prolyl cis-trans isomerase-like 3 & 0.000 & 0.179 \\
\hline
\end{tabular}

Group 3, upper-left lip of fetus at $72 \mathrm{~h}$ after modeling in GA18.5 rats; Group 4, upper-right lip of fetus at $72 \mathrm{~h}$ after modeling in GA18.5 rats. GA, gestational age. 
Table IV. Differential protein expression in group 3 and group 1.

\begin{tabular}{|c|c|c|c|c|}
\hline Protein ID & Gene name & Protein name & P-value & Fold change \\
\hline Q6jhy3 & Smgc & Submandibular gland protein c precursor & 0.001 & 753.286 \\
\hline D3zge 2 & Mpo & Myeloperoxidase precursor & 0.000 & 271.832 \\
\hline Q62714 & $\mathrm{Np} 4$ & Neutrophil antibiotic peptide np-4 & 0.000 & 244.647 \\
\hline D3zmi6 & Olfm4 & Olfactomedin-4 precursor & 0.000 & 189.639 \\
\hline D3zy96 & $\mathrm{Ngp}$ & Neutrophilic granule protein precursor & 0.014 & 130.459 \\
\hline B2ryb8 & $\operatorname{Itgb} 2$ & Integrin beta 2 precursor & 0.002 & 44.874 \\
\hline G3v817 & Itgam & Integrin alpha-m precursor & 0.012 & 32.024 \\
\hline Q6ig02 & Krt2 & Keratin, type ii cytoskeletal 2 epidermal & 0.011 & 26.577 \\
\hline Q63015 & Csap1 & Common salivary protein 1 precursor & 0.003 & 26.571 \\
\hline P50115 & S100a8 & S100 calcium binding protein a 8 & 0.002 & 25.933 \\
\hline P50116 & S100a9 & S100 calcium binding protein a9 & 0.001 & 19.538 \\
\hline Q9jkb7 & Gda & Guanine deaminase & 0.023 & 19.076 \\
\hline D3zd07 & Fmo9 & Flavin containing monooxygenase 9 pseudogene & 0.003 & 17.428 \\
\hline Q5u1y2 & Rac2 & Ras-related c3 botulinum toxin substrate 2 & 0.011 & 12.859 \\
\hline O54854 & Klk6 & Kallikrein-6 precursor & 0.000 & 10.614 \\
\hline Q5u2v4 & Plbd1 & Phospholipase b-like 1 & 0.002 & 10.508 \\
\hline Q6pdv1 & Lyz1 & Lysozyme c-1 precursor & 0.002 & 8.631 \\
\hline Q4g075 & Serpinb1a & Leukocyte elastase inhibitor a & 0.001 & 8.260 \\
\hline Q6ldz3 & Ptprc & Receptor-type tyrosine-protein phosphatase c & 0.023 & 8.077 \\
\hline Q9wuq4 & Slpi & Secretory leukocyte peptidase inhibitor precursor & 0.007 & 7.093 \\
\hline Q9erl1 & Cybb & Cytochrome b-245, beta polypeptide & 0.009 & 7.056 \\
\hline E0a3n4 & Serpina3n & Serine protease inhibitor $\mathrm{a} 3 \mathrm{n}$ & 0.013 & 7.049 \\
\hline G3v6k1 & $\operatorname{Tcn} 2$ & Transcobalamin-2 precursor & 0.017 & 6.577 \\
\hline P14669 & Anxa3 & Annexin a3 & 0.010 & 5.005 \\
\hline P22985 & $\mathrm{Xdh}$ & Xanthine dehydrogenase/oxidase & 0.003 & 4.802 \\
\hline Q91zn1 & Coro1a & Coronin-1a & 0.001 & 4.694 \\
\hline P05982 & Nqo1 & Nad(p)h quinone dehydrogenase 1 & 0.001 & 4.334 \\
\hline P23640 & Rab27a & Ras-related protein rab-27a & 0.019 & 3.830 \\
\hline Q6ifu9 & Krt16 & Keratin, type i cytoskeletal 16 & 0.001 & 3.797 \\
\hline Q62894 & Ecm1 & Extracellular matrix protein 1 & 0.039 & 3.655 \\
\hline Q5xi38 & Lcp1 & Plastin-2 & 0.003 & 3.469 \\
\hline P07150 & Anxa1 & Annexin a1 & 0.003 & 3.446 \\
\hline Q78zr5 & Hopx & Homeodomain-only protein & 0.002 & 3.376 \\
\hline P01015 & Agt & Angiotensinogen angiotensin- 1 angiotensin- 2 angiotensin- 3 & 0.010 & 3.300 \\
\hline Q6axy8 & Dhrs1 & Dehydrogenase/reductase sdr family member 1 & 0.006 & 3.287 \\
\hline Q91w30 & Akr1b8 & Aldose reductase-related protein 2 & 0.007 & 3.244 \\
\hline P32755 & Hpd & 4-hydroxyphenylpyruvate dioxygenase & 0.024 & 3.149 \\
\hline Q499n7 & Ptpn6 & Tyrosine-protein phosphatase non-receptor type 6 & 0.038 & 3.025 \\
\hline G3v755 & Sprr1a & Cornifin-a & 0.002 & 3.006 \\
\hline Q5xfv4 & Fabp4 & Fatty acid-binding protein, adipocyte & 0.024 & 2.910 \\
\hline B1wbv8 & Pld4 & Phospholipase d4 & 0.011 & 2.909 \\
\hline D3zpf9 & Serpinb12 & Serpin b12 & 0.038 & 2.880 \\
\hline Q4qqv6 & Lsp1 & Lymphocyte specific 1 & 0.001 & 2.665 \\
\hline P29524 & Serpinb2 & Plasminogen activator inhibitor 2 type a & 0.001 & 2.653 \\
\hline O55162 & Lypd3 & Ly6/plaur domain-containing protein 3 & 0.004 & 2.551 \\
\hline D4a5u3 & $\operatorname{Tgm} 3$ & Protein-glutamine gamma-glutamyltransferase e protein & 0.033 & 2.547 \\
\hline D3zsh7 & Col17a1 & Collagen alpha-1(xvii) chain & 0.002 & 2.485 \\
\hline D3zjk2 & Serpinb3a & Protein serpinb3a & 0.038 & 2.445 \\
\hline Q6ie17 & Stfa212 & Stefin-3 & 0.005 & 2.439 \\
\hline Q5u206 & Calml3 & Calmodulin-like protein 3 & 0.013 & 2.429 \\
\hline Q4v885 & Colec12 & Collectin-12 & 0.017 & 0.547 \\
\hline D3zqi1 & Gpx7 & Glutathione peroxidase 7 precursor & 0.036 & 0.541 \\
\hline
\end{tabular}


Table IV. Continued.

\begin{tabular}{|c|c|c|c|c|}
\hline Protein ID & Gene name & Protein name & P-value & Fold change \\
\hline D3z9m5 & Fkbp7 & Peptidyl-prolyl cis-trans isomerase fkbp7 precursor & 0.014 & 0.530 \\
\hline O88201 & Clec11a & C-type lectin domain family 11 member a & 0.047 & 0.529 \\
\hline D3zrd3 & Pde6d & $\begin{array}{l}\text { Retinal rod rhodopsin-sensitive cgmp } 3^{\prime}, 5^{\prime} \text {-cyclic } \\
\text { phosphodiesterase subunit delta }\end{array}$ & 0.009 & 0.528 \\
\hline P21807 & Prph & Peripherin & 0.008 & 0.527 \\
\hline G3v6m4 & Capn6 & Calpain-6 & 0.024 & 0.514 \\
\hline D3zg88 & Sssca 1 & Sjogren syndrome/scleroderma autoantigen 1 homolog & 0.034 & 0.502 \\
\hline Q2eja0 & Yap1 & Yorkie homolog & 0.002 & 0.494 \\
\hline Q3b7u1 & Maged2 & Melanoma-associated antigen $\mathrm{d} 2$ & 0.003 & 0.492 \\
\hline O35276 & Nrp2 & Neuropilin-2 & 0.015 & 0.491 \\
\hline D3zun5 & Pofut2 & Gdp-fucose protein o-fucosyltransferase 2 precursor & 0.018 & 0.490 \\
\hline P70583; d4a6v3 & Dut & Deoxyuridine 5'-triphosphate nucleotidohydrolase & 0.021 & 0.489 \\
\hline P19527 & Nefl & Neurofilament light polypeptide & 0.026 & 0.479 \\
\hline M0r649 & Exoc4 & Exocyst complex component 4 & 0.031 & 0.466 \\
\hline Q99pd6 & Tgfbli1 & Transforming growth factor beta-1-induced transcript 1 protein & 0.048 & 0.466 \\
\hline P54001 & P4ha1 & Prolyl 4-hydroxylase subunit alpha-1 & 0.019 & 0.461 \\
\hline D3zt07 & Sept5 & Septin-5 & 0.046 & 0.452 \\
\hline P12839; g3v7s2 & Nefm & Neurofilament medium polypeptide & 0.020 & 0.444 \\
\hline B5df50 & Galnt2 & Polypeptide n-acetylgalactosaminyltransferase 2 & 0.038 & 0.436 \\
\hline D3zuq0 & Rilpl1 & Rilp-like protein 1 & 0.041 & 0.418 \\
\hline D4a8h3 & Uba6 & Ubiquitin-like modifier-activating enzyme 6 & 0.024 & 0.415 \\
\hline D4a9u4 & Eln & Elastin & 0.041 & 0.409 \\
\hline D4ad75 & Dpy1911 & Protein dpy-19 homolog 1 & 0.014 & 0.408 \\
\hline Q6p7d4 & Cyp20a1 & Cytochrome p450 20a1 & 0.007 & 0.406 \\
\hline Q5xi28 & Raver1 & Ribonucleoprotein ptb-binding 1 & 0.045 & 0.398 \\
\hline P09117 & Aldoc & Fructose-bisphosphate aldolase c & 0.004 & 0.396 \\
\hline D3zct5 & Pald1 & Paladin & 0.004 & 0.395 \\
\hline A $111 \mathrm{k} 3$ & Anapc5 & Anaphase-promoting complex subunit 5 & 0.028 & 0.392 \\
\hline P62966 & Crabp1 & Cellular retinoic acid-binding protein 1 & 0.016 & 0.384 \\
\hline Q569b7 & Rwdd4 & Rwd domain-containing protein 4 & 0.040 & 0.384 \\
\hline Q5hze4 & Mri1 & Methylthioribose-1-phosphate isomerase & 0.011 & 0.376 \\
\hline F1lqz3 & Kif3a & Kinesin family member $3 a$ & 0.011 & 0.376 \\
\hline O88752 & Hbe1 & Hemoglobin, epsilon 1 & 0.033 & 0.375 \\
\hline Q5u1z0 & Rab3gap2 & Rab3 gtpase-activating protein non-catalytic subunit & 0.003 & 0.373 \\
\hline A1a5r1 & Rbfox1 & Fox-1 homolog c & 0.033 & 0.366 \\
\hline D4a845 & Rpa3 & Replication protein a 14 kda subunit & 0.021 & 0.366 \\
\hline D3zwc6 & Sntb1 & Beta-1-syntrophin & 0.003 & 0.365 \\
\hline G3v8m1 & Pold1 & Dna polymerase delta catalytic subunit & 0.003 & 0.353 \\
\hline P23565 & Ina & Alpha-internexin & 0.039 & 0.352 \\
\hline Q4klk9 & Ssu72 & Rna polymerase ii subunit a c-terminal domain phosphatase ssu 72 & 0.025 & 0.349 \\
\hline F1mah6 & Cdh11 & Cadherin 11 & 0.007 & 0.326 \\
\hline Q6ayg3 & Prune & Prune homolog (drosophila) (ec:3.6.1.1) & 0.001 & 0.278 \\
\hline P04638 & Apoa2 & Apolipoprotein a-ii & 0.010 & 0.270 \\
\hline Q9z2z8 & Dhcr7 & 7-dehydrocholesterol reductase & 0.000 & 0.221 \\
\hline Q10758 & Krt8 & Keratin, type ii cytoskeletal 8 & 0.002 & 0.214 \\
\hline Q812d3 & Ppil3 & Peptidyl-prolyl cis-trans isomerase-like 3 & 0.000 & 0.188 \\
\hline G3v8r3 & $\mathrm{Hbz}$ & Hemoglobin, zeta & 0.004 & 0.128 \\
\hline B5dfl9 & Sestd 1 & Sec14 and spectrin domains 1 & 0.000 & 0.065 \\
\hline Q9eph1 & A1bg & Alpha-1b-glycoprotein & 0.016 & 0.033 \\
\hline
\end{tabular}

Group 1, upper-left lip of fetus at $72 \mathrm{~h}$ after modeling in GA16.5 rats; Group 3, upper-left lip of fetus at $72 \mathrm{~h}$ after modeling in GA18.5 rats. GA, gestational age. 


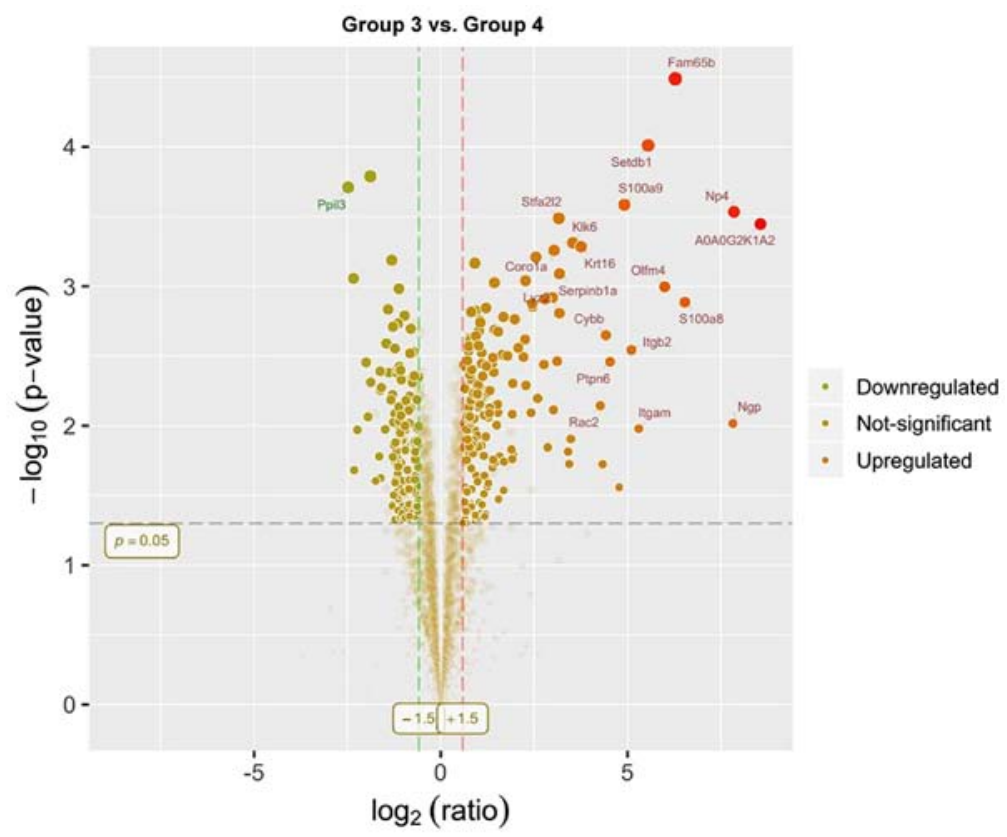

Figure 11. Volcano plot of the differentially expressed proteins in group 3 and group 4 . Group 3, upper-left lip of fetus at $72 \mathrm{~h}$ after modeling in GA18.5 rats; Group 4, upper-right lip of fetus at $72 \mathrm{~h}$ after modeling in GA18.5 rats. GA, gestational age.

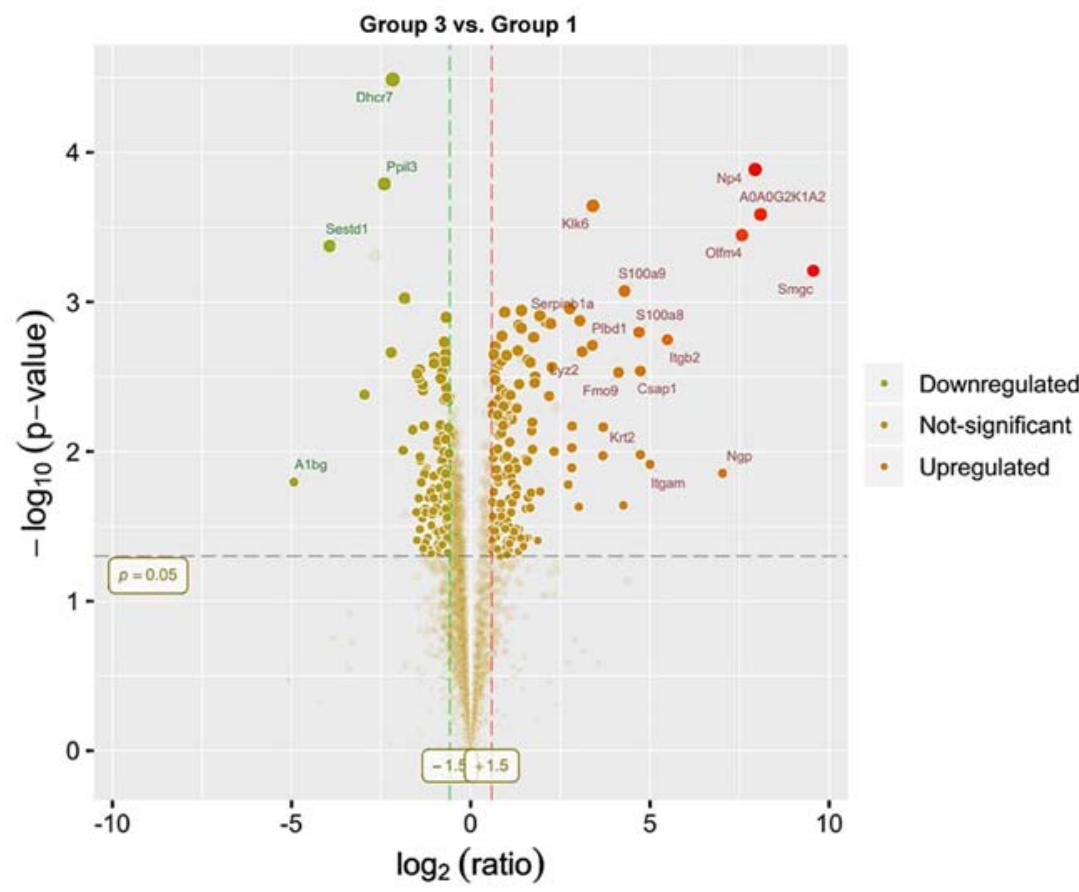

Figure 12. Volcano plot of the differentially expressed proteins in group 3 and group 1. Group 1, upper-left lip of fetus at $72 \mathrm{~h}$ after modeling in GA16.5 rats; Group 3, upper-left lip of fetus at $72 \mathrm{~h}$ after modeling in GA18.5 rats. GA, gestational age.

RT-qPCR analysis of possible target protein in cleft lip repair. RNA was extracted from tissue samples with $\mathrm{TRIzol}^{\circledR}$ reagent and the quality was checked using gel electrophoresis. Relative mRNA levels were analyzed using RT-qPCR (Fig. 16). The relative mRNA expression levels of Smad4 were significantly higher in group 2, compared with group $1(\mathrm{P}<0.05)$. Moreover, the relative mRNA expression levels of Fabp5 were significantly lower in groups 4 and 1, compared with group $3(\mathrm{P}<0.05)$. Additionally, the relative mRNA expression levels of S100a4 were significantly lower in group 4, compared with group $3(\mathrm{P}<0.05)$. S100a8 and S100a9 were significantly higher in group 3 , compared with in groups 1 and $4(\mathrm{P}<0.05)$.

Immunofluorescence results. Immunofluorescence staining of Smad4, Fabp5, S100a4, S100a8 and S100a9 was performed on samples from both the GA16.5 and GA18.5 groups $72 \mathrm{~h}$ post-surgery. The expression levels of all five proteins increased in GA18.5 compared to GA16.5, and the differences were statistically significant $(\mathrm{P}<0.05$; Fig. 17). 

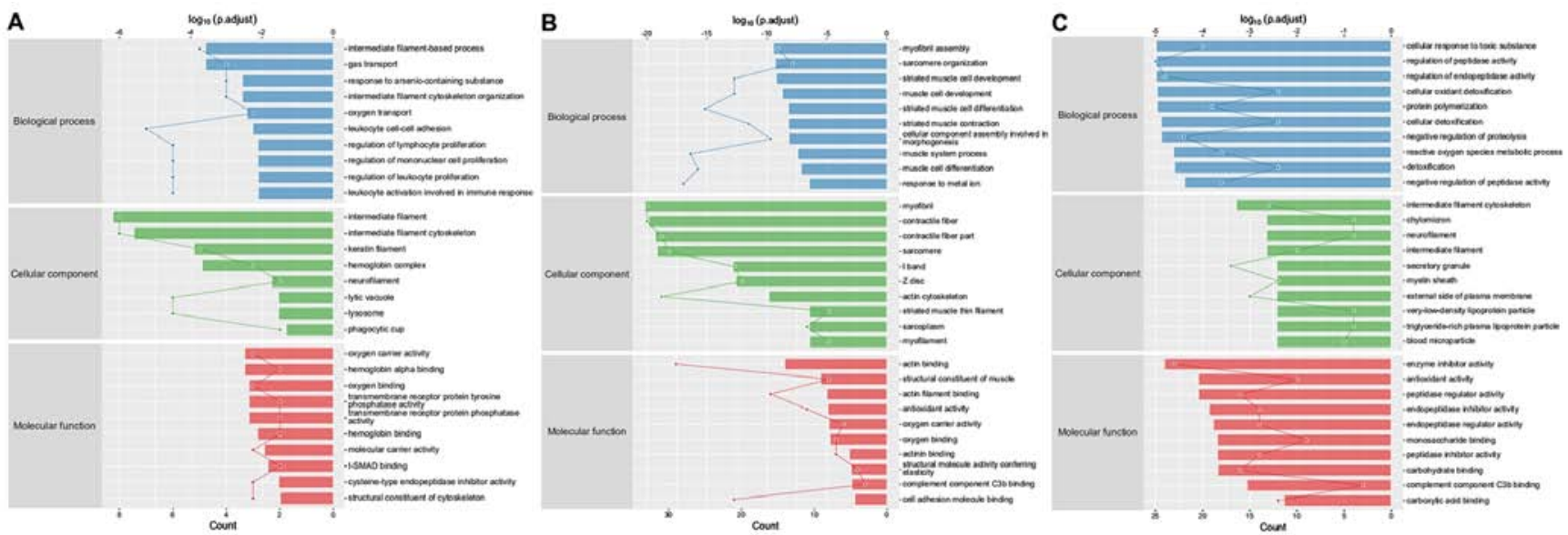

Figure 13. GO enrichment analysis of the differentially expressed proteins. GO enrichment analysis of the differentially expressed proteins in (A) group 1 and group 2, (B) in group 3 and group 4 and (C) in group 3 and group 1. GA, gestational age; GO, Gene Ontology; p.adjust, adjusted P-value. Group 1, upper-left lip of fetus at $72 \mathrm{~h}$ after modeling in GA16.5 rats; Group 2, upper-right lip of fetus at $72 \mathrm{~h}$ after modeling in GA16.5 rats; Group 3, upper-left lip of fetus at $72 \mathrm{~h}$ after modeling in GA18.5 rats; Group 4, upper-right lip of fetus at $72 \mathrm{~h}$ after modeling in GA18.5 rats. GA, gestational age.

A

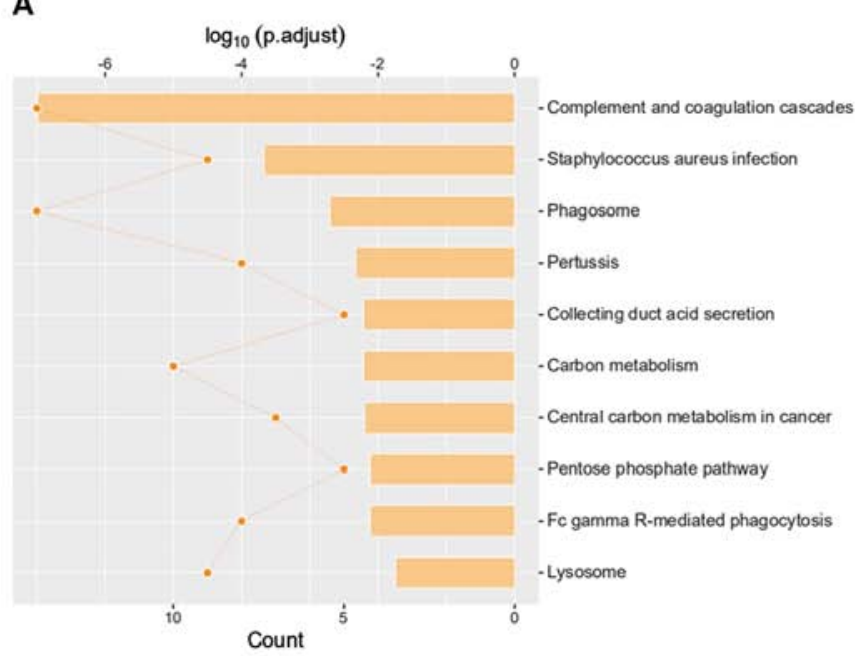

B

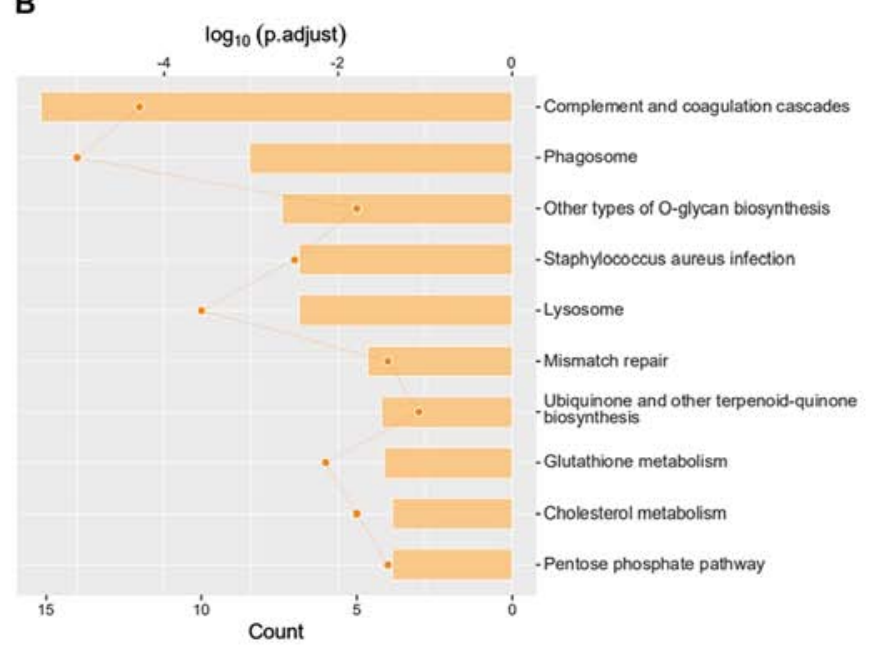

Figure 14. KEGG pathway enrichment analysis of the differentially expressed proteins. KEGG pathway enrichment analysis of the differentially expressed proteins in (A) group 3 and group 4 and (B) in group 3 and group 1. GA, gestational age; KEGG, Kyoto Encyclopedia of Genes and Genomes; p.adjust, adjusted P-value. Group 1, upper-left lip of fetus at $72 \mathrm{~h}$ after modeling in GA16.5 rats; Group 2, upper-right lip of fetus at $72 \mathrm{~h}$ after modeling in GA16.5 rats; Group 3 , upper-left lip of fetus at $72 \mathrm{~h}$ after modeling in GA18.5 rats; Group 4, upper-right lip of fetus at $72 \mathrm{~h}$ after modeling in GA18.5 rats. GA, gestational age.

PRM analysis of differential protein expression. The differences in multiple variations of Smad4 expression were compared between groups 1 and 2 . The panel reaction monitoring calculated this difference as 0.557 , indicating downregulation in group 1 compared with in group 2 $(\mathrm{P}=0.043)$ (Table II). In contrast, no statistically significant differences were observed between groups 3 and 4 . The difference in multiple variations of Fabp5 between groups 3 and 4 was calculated as 2.91, indicating upregulation in group 3 compared with in group $4(\mathrm{P}=0.024)$ (Table III). Additionally, the expression levels of Fabp5 were upregulated $(\mathrm{P}=0.01)$ in group 3 compared with in group 1; however, the difference between the variations present in groups 1 and 2 was not statistically significant. The difference in the multiple variations of S100a4 and S100a8 between groups 3 and 4 was calculated as 2.897 and 92.828 , respectively, indicating an upregulation of the expression levels of both proteins in group $3(\mathrm{P}=0.001$ and
$\mathrm{P}=0.002$, respectively) (Table III). Furthermore, the difference in the multiple variations of S100a8 between groups 3 and 1 was 25.933, which indicates upregulation in group $3(\mathrm{P}=0.002)$ (Table IV). However, the differences were not statistically significant between groups 1 and 2. The difference in the multiple variations of S100a9 was 30.191 and 19.538 between groups 3 and 4 and groups 3 and 1, respectively, suggesting upregulation in group 3 ( $\mathrm{P}=0.0004$ and $\mathrm{P}=0.001$, respectively) (Tables III and IV). In contrast, the difference in the multiple variations of S100a9 between groups 1 and 2 was not statistically significant (Tables II-IV).

\section{Discussion}

In recent decades, various animal models of congenital cleft lip have been successfully established through surgical induction $(4,20)$. It has been suggested that intrauterine cleft 
A

Interactions: 80
Expected interactions: $35(\mathrm{P}<0.0001)$

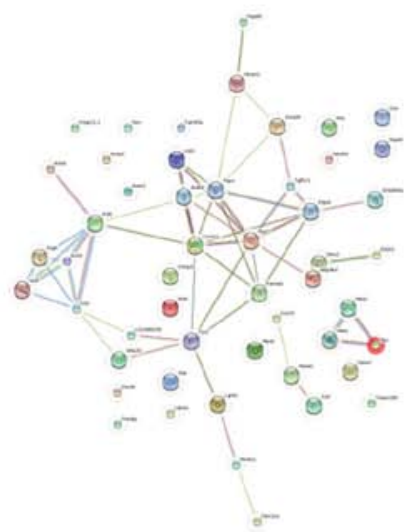

B

Interactions: 2,348
Expected interactions: $1,081(P<0.0001)$

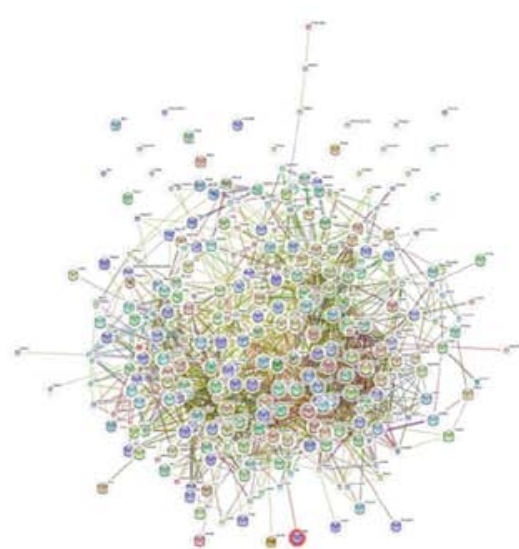

C

Proteins: 256

Interactions: 1,555

Expected interactions: $842(\mathrm{P}<0.0001)$

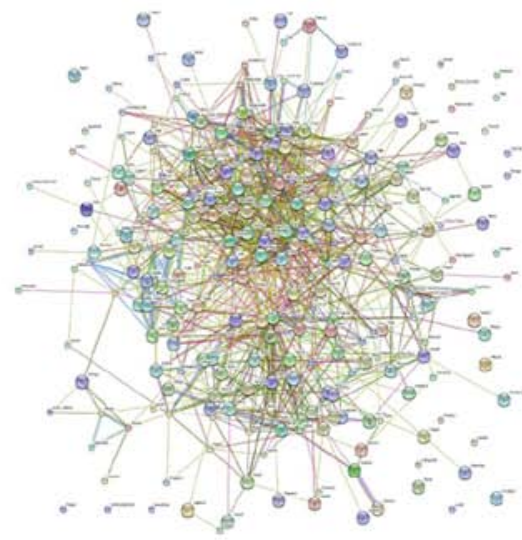

Figure 15. Interaction network of differentially expressed proteins. Interaction network of differentially expressed proteins in (A) group 1 and group 2 , (B) 3 and group 4 and (C) 3 and group 1. Group 1, upper-left lip of fetus at $72 \mathrm{~h}$ after modeling in GA16.5 rats; Group 2, upper-right lip of fetus at $72 \mathrm{~h}$ after modeling in GA16.5 rats; Group 3, upper-left lip of fetus at $72 \mathrm{~h}$ after modeling in GA18.5 rats; Group 4, upper-right lip of fetus at $72 \mathrm{~h}$ after modeling in GA18.5 rats. GA, gestational age.
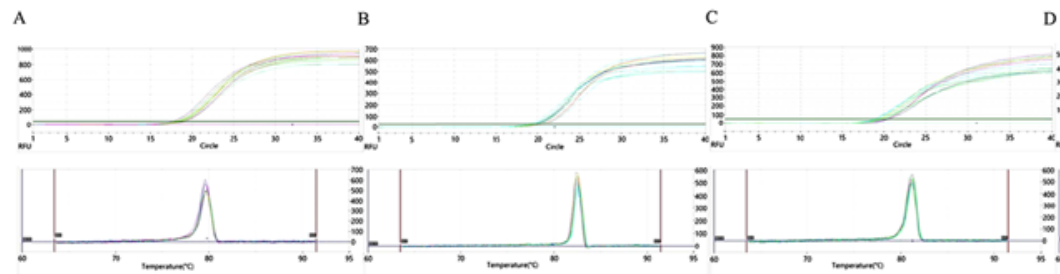

D
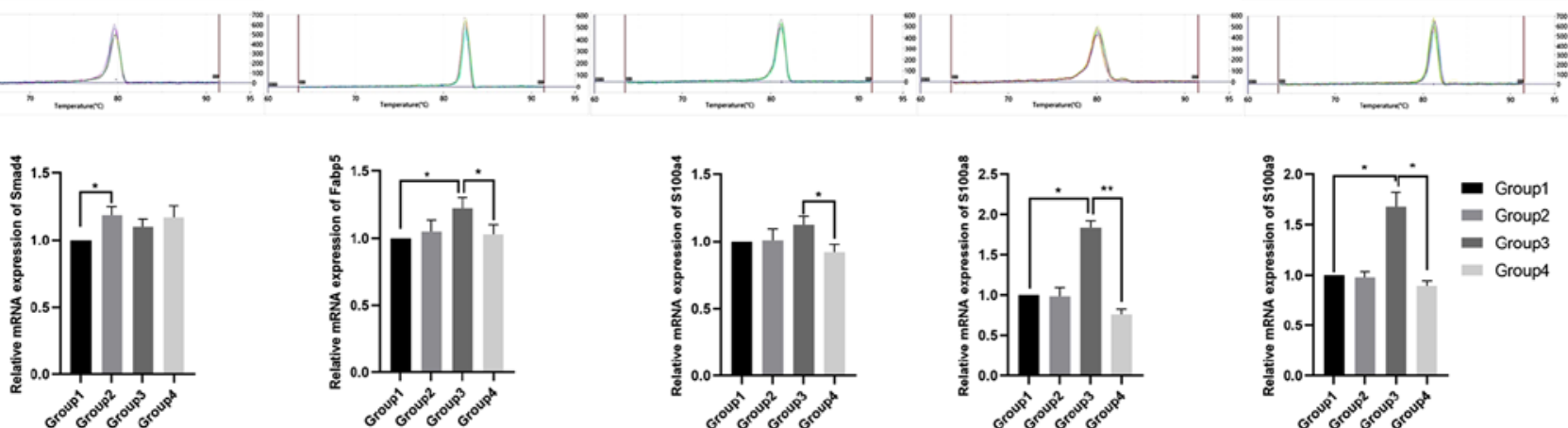

Figure 16. RT-qPCR analysis of Smad4, Fabp5, S100a4, S100a8 and S100a9. RT-qPCR detection and amplification of (A) Smad4, (B) Fabp5, (C) S100a4, (D) S100a8 and (E) S100a9. The dissolution curves and relative mRNA expression levels are shown for each target. RT-qPCR, reverse transcription-quantitative PCR; Fabp5, fatty acid binding protein 5; Smad4, Smad family member 4; S100, S100 calcium binding protein. Group 1, upper-left lip of fetus at $72 \mathrm{~h}$ after modeling in GA16.5 rats; Group 2, upper-right lip of fetus at $72 \mathrm{~h}$ after modeling in GA16.5 rats; Group 3, upper-left lip of fetus at $72 \mathrm{~h}$ after modeling in GA18.5 rats; Group 4, upper-right lip of fetus at $72 \mathrm{~h}$ after modeling in GA18.5 rats. ${ }^{*} \mathrm{P}<0.05 ;{ }^{* *} \mathrm{P}<0.01$. GA, gestational age.

lip repair can effectively improve this defect and reduce the impact of scars on normal facial development after birth. Thus, it also provides a new way for the effective repair of congenital cleft lips. In the present study, pregnant SD rats were used to establish a fetal rat model of cleft lip wound at two time points, GA16.5 and GA18.5. The different pregnancy models were induced by using two different repair methods of a cleft lip wound of the fetus $(21,22)$. The exact gestational age is particularly important for the results of the repair of cleft lip in the fetal rats. Thus, the use of a rat model provides an added advantage in that the exact time of conception can be replicated, thereby minimizing differences between groups.

The present findings confirmed the hypothesis that fetal rat defects can be regenerated during early pregnancy without scar formation (23). It was also demonstrated that fetal rat defects could not be completely regenerated in late pregnancy and resulted in scarring (24). Furthermore, the expression of pro-inflammatory factors was different between the two groups. However, these observations were only made at one time point $(72 \mathrm{~h}$ ) after constructing cleft lip wounds in fetal rats. Future studies are needed to examine samples collected at different time points following surgery. Another shortcoming of this study entails the lack of comparison between the cleft lip wound repairs of fetal rats at different ages, such as the fetus in the early stages of pregnancy, or in newborn and/or adult rats. Label-free quantitative proteomics were used to examine proteins that play important roles in the postoperative repair process of fetal cleft lip. Protein expression was examined in four groups of samples. In addition, bioinformatics analysis was conducted to identify potential 
A
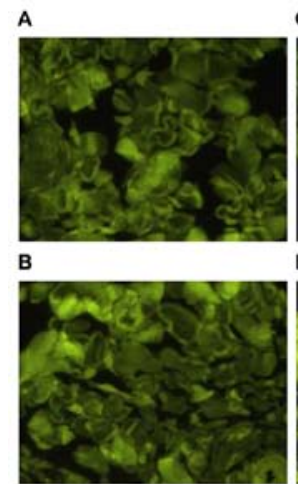

K 2.5

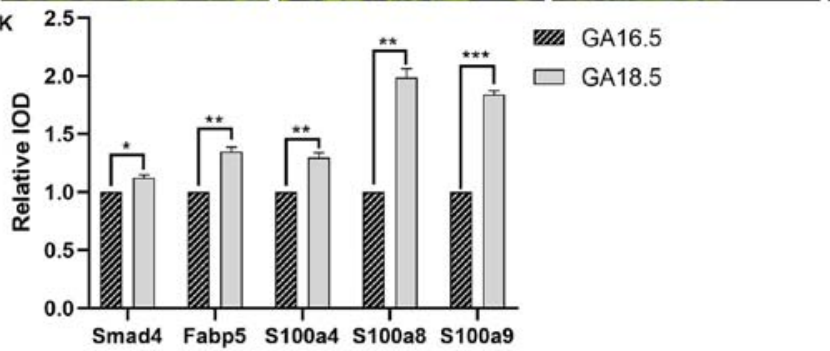

G
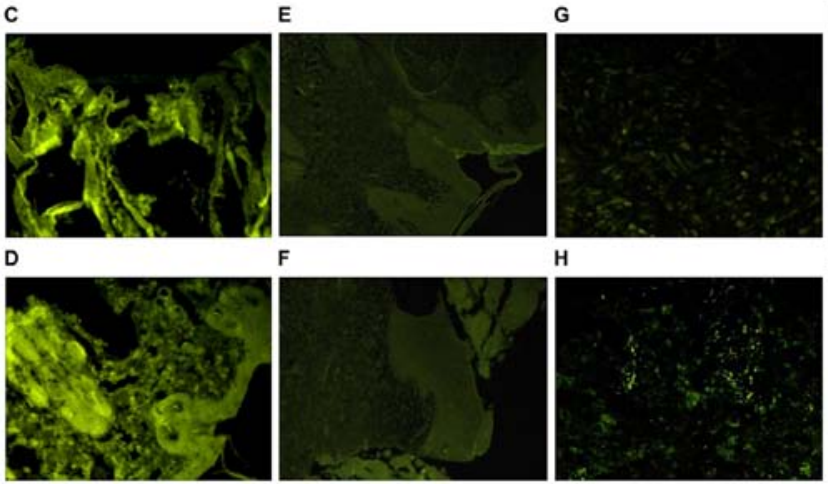

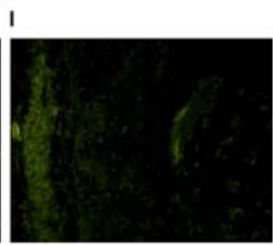

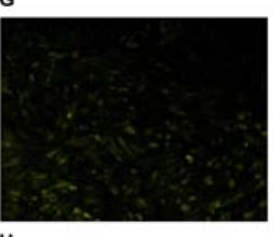

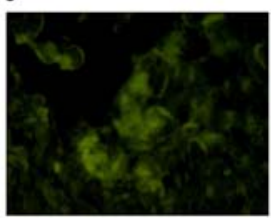

(Am and (B) the GA18.5 group. (C and D) Fabp5 staining of upper lip tissue from (C) the GA16.5 group and (D) the GA18.5 group. (E and F) S100a4 staining of upper lip tissue from (F) the GA16.5 group and (F) the GA18.5 group. (G and H) S100a8 staining of upper lip tissue from (G) the GA16.5 group and (H) the GA18.5 group. (I and J) S100a9 staining of upper lip tissue from (I) the GA16.5 group and (J) the GA18.5 group. (K) Relative IOD values for Smad4, Fabp5, S100a4, S100a8 and S100a9 staining. ${ }^{*} \mathrm{P}<0.05 ;{ }^{* *} \mathrm{P}<0.01 ;{ }^{* * *} \mathrm{P}>0.001$. Fabp5, fatty acid binding protein 5; Smad4, Smad family member 4; S100, S100 calcium binding protein; IOD, integral optical density; GA, gestational age.

biological markers, providing a theoretical reference and methodological basis for the examination of relevant mechanisms underlying fetal intrauterine scar repair. However, further studies are required to determine whether any one protein or several proteins, plays a key role in wound healing.

Smad4 belongs to the family of Smad proteins and is a common mediator in the signal transduction processes of the TGF- $\beta$ family (25). TGF- $\beta$ expression can lead to fibroblast proliferation and ECM deposition $(26,27)$. The present findings indicated that the mRNA and protein expression levels of Smad4 were downregulated in the scar-free repair group.

Furthermore, the mRNA and protein expression levels of Fabp5 were upregulated in the scar formation group. Therefore, it may be hypothesized that Fabp5 could be involved in the fibrosis of the fetal cleft lip wound, which may be mediated by the TGF- $\beta$ signaling pathway (28-30).

S100a4 is a member of the S100 calcium-binding protein family, and its expression is associated with various non-neoplastic diseases, such as chronic obstructive pulmonary disease and cardiac hypertrophy (31-35). The present study demonstrated that the mRNA and protein expression levels of S100a4 were upregulated in the scar formation group, which may be associated with scar repair of fetal rat cleft lip wounds.

S100a8 is also a member of the S100 calcium-binding protein family (36-42). mRNA and protein expression levels of S100a8 were significantly upregulated in the scar repair group in the present study, indicating a potential role for $\mathrm{S} 100 \mathrm{a} 8$ in the process of fetal cleft lip wound healing.

Current reports frequently associate S100a9, a member of the calcium-binding protein family S100, with infectious diseases, immune diseases and tumors, such as non-small cell lung adenocarcinoma (43-45). mRNA and protein expression levels of S100a9 were significantly upregulated in the scar formation group. Therefore, we speculated that S100a9 may play an important role in the process of fetal wound healing. However, whether the reduced expression levels of Fabp5, S100a4, S100a8 and S100a9 in the third trimester of pregnancy would reduce or worsen scar formation remains unclear. Further functional testing and regulatory studies are required to confirm the role of these five differentially expressed proteins in fetal wound repair.

The cleft lip is a very common congenital condition that often leaves life-long scarring. The present study identified five differentially expressed proteins, namely Smad4, Fabp5, S100a4, S100a8 and S100a9, that may be potential biomarkers of the scarless repair process in fetal rat cleft lip wounds. These findings may facilitate the discovery of new clinical targets for the prevention and treatment of scars. However, the role of these proteins in fetal wound repair and potential underlying mechanisms require further examination.

\section{Acknowledgements}

Not applicable.

\section{Funding}

The present study was supported by a grant from the National Science and Basic Resources Survey Special Foundation, China (grant no. 2017FY101204), the Technology Innovation Guide Program of Hunan Province, China (grant no. 2017SK50124), the Science and Technology Major Project of Hunan Province, China (grant no. 2019SK1010) and 
the Science and Technology Major Project of Hunan Province, China (grant no. 2019SK1015).

\section{Availability of data and materials}

The datasets used and/or analyzed during the current study are available from the corresponding author on reasonable request.

\section{Authors' contributions}

YY, FH and JZho conceived and designed research. YY and $\mathrm{FH}$ performed animal experiments and staining. YY, HL, PJ, FH, JY, KG, SH and JZha performed PCR and label-free quantification PRM. YY, FH, JC, JY, ZC, AW and JZha analyzed data. YY and FH prepared figures. YY drafted the manuscript. FH and JZho edited and revised the manuscript. YY, FH, HL AW, PJ and JZho approved the final version of the manuscript. FH and JZho confirmed the authenticity of all of the raw data. All authors read and approved the final manuscript.

\section{Ethics approval and consent to participate}

This study followed the regulations stipulated by the People's Republic of China regarding the Management of Experimental Animals and was approved by The Animal Experiment Management and Medical Ethics Sub-committee of The Third Xiangya Hospital of Central South University, Hunan, China (approval no. 2014-S168).

\section{Patient consent for publication}

Not applicable.

\section{Competing interests}

The authors declare that they have no competing interests.

\section{References}

1. VanKoevering KK, Morrison RJ, Prabhu SP, Torres MF, Mychaliska GB, Treadwell MC, Hollister SJ and Green GE: Antenatal three-dimensional printing of aberrant facial anatomy. Pediatrics 136: e1382-e1385, 2015.

2. Burrington JD: Wound healing in the fetal lamb. J Pediatr Surg 6: 523-528, 1971.

3. Beanes SR, Hu FY, Soo C, Dang CM, Urata M, Ting K, Atkinson JB, Benhaim P, Hedrick MH and Lorenz HP: Confocal microscopic analysis of scarless repair in the fetal rat: Defining the transition. Plast Reconstr Surg 109: 160-170, 2002.

4. Walmsley GG, Hu MS, Hong WX, Maan ZN, Lorenz HP and Longaker MT: A mouse fetal skin model of scarless wound repair. J Vis Exp 16: 52297, 2015.

5. Dang CM, Beanes SR, Lee H, Zhang X, Soo C and Ting K: Scarless fetal wounds are associated with an increased matrix metalloproteinase-to-tissue-derived inhibitor of metalloproteinase ratio. Plast Reconstr Surg 111: 2273-2285, 2003.

6. Longaker MT, Whitby DJ, Adzick NS, Crombleholme TM, Langer JC, Duncan BW, Bradley SM, Stern R, Ferguson MW and Harrison MR: Studies in fetal wound healing, VI. Second and early third trimester fetal wounds demonstrate rapid collagen deposition without scar formation. J Pediatr Surg 25: 63-69, 1990.

7. Lorenz HP, Whitby DJ, Longaker MT and Adzick NS: Fetal wound healing. The ontogeny of scar formation in the non-human primate. Ann Surg 217: 391-396, 1993.
8. Cass D, Bullard KM, Sylvester KG, Yang EY, Longaker MT and Adzick NS: Wound size and gestational age modulate scar formation in fetal wound repair. J Pediatr Surg 32: 411-415, 1997.

9. Longaker MT and Adzick NS: The biology of fetal wound healing: A review. Plast Reconstr Surg 87: 788-798, 1991.

10. Armstrong JR and Ferguson MW: Ontogeny of the skin and the transition from scar-free to scarring phenotype during wound healing in the pouch young of a marsupial, Monodelphis domestica. Dev Biol 169: 242-260, 1995.

11. Stern M, Dodson TB, Longaker MT, Lorenz HP, Harrison MR and Kaban LB: Fetal cleft lip repair in lambs: Histologic characteristics of the healing wound. Int J Oral Maxillofac Surg 22: 371-374, 1993.

12. Longaker MT, Dodson TB and Kaban LB: A rabbit model for fetal cleft lip repair. J Oral Maxillofac Surg 48: 714-719, 1990.

13. Oberg KC, Evans ML, Nguyen T, Peckham NH, Kirsch WM and Hardesty RA: Intrauterine repair of surgically created defects in mice (lip incision model) with a microclip: Preamble to endoscopic intrauterine surgery. Cleft Palate Craniofac J 32: 129-137, 1995.

14. Hu F, Yan Y, Wang CW, Liu Y, Wang JJ,Zhou F, Zeng QH, Zhou X, Chen J, Wang AJ and Zhou JD: Article effect and mechanism of ganoderma lucidum polysaccharides on human fibroblasts and skin wound healing in mice. Chin J Integr Med 25: 203-209, 2019.

15. Xue YN, Yan Y, Chen ZZ, Chen J, Tang FJ, Xie HQ, Tang SJ, Cao K, Zhou X, Wang AJ and Zhou JD: LncRNA TUG1 regulates FGF1 to enhance endothelial differentiation of adipose-derived stem cells by sponging miR-143. J Cell Biochem 120: 19087-19097, 2019.

16. Guo H, Chen T, Liang Z, Fan L, Shen Y and Zhou D: iTRAQ and PRM-based comparative proteomic profiling in gills of white shrimp Litopenaeus vannamei under copper stress. Chemosphere 263: 128270, 2021

17. Chen PS, Li YP and Ni HF: Morphology and evaluation of renal fibrosis. Adv Exp Med Biol 1165: 17-36, 2019.

18. Luo Y, Yan Y, Zhang S and Li Z: Computational approach to investigating key GO terms and KEGG pathways associated with CNV. Biomed Res Int 2018: 8406857, 2018.

19. Dong X, Landford WN, Hart J, Risolino M, Kaymakcalan O, Jin J, Toyoda Y, Ferretti E, Selleri L and Spector JA: Toward microsurgical correction of cleft lip ex utero through restoration of craniofacial developmental programs. Plast Reconstr Surg 140: 75-85, 2017.

20. Stelnicki EJ, Lee S, Hoffman W, Lopoo J, Foster R, Harrison MR and Longaker MT: A long-term, controlled-outcome analysis of in utero versus neonatal cleft lip repair using an ovine model. Plast Reconstr Surg 104: 607-615, 1999.

21. Harling TR, Stelnicki EJ, Hedrick MH and Longaker MT: In utero models of craniofacial surgery. World J Surg 27: 108-116, 2003.

22. Mast BA, Haynes JH, Krummel TM, Diegelmann RF and Cohen IK: In vivo degradation of fetal wound hyaluronic acid results in increased fibroplasia, collagen deposition, and neovascularization. Plast Reconstr Surg 89: 503-509, 1992.

23. Frantz FW, Diegelmann RF, Mast BA and Cohen IK: Biology of fetal wound healing: Collagen biosynthesis during dermal repair. J Pediatr Surg 27: 945-949, 1992.

24. Wilgus TA: Regenerative healing in fetal skin: A review of the literature. Ostomy Wound Manage 53: 16-33, 2007.

25. Hu HH, Chen DQ, Wang YN, Feng YL, Cao G, Vaziri ND and Zhao YY: New insights into TGF-beta/Smad signaling in tissue fibrosis. Chem Biol Interac 292: 76-83, 2018.

26. Honardoust D, Ding J, Varkey M, Shankowsky HA and Tredget EE: Deep dermal fibroblasts refractory to migration and decorin-induced apoptosis contribute to hypertrophic scarring. J Burn Care Res 33: 668-677, 2012.

27. Wu C, Jiang J, Boye A, Jiang Y and Yang Y: Compound Astragalus and Salvia miltiorrhiza extract suppresses rabbits' hypertrophic scar by modulating the TGF- $\beta /$ Smad signal. Dermatology 229: 363-368, 2014

28. Furuhashi M, Ogura M, Matsumoto M, Yuda S, Muranaka A, Kawamukai M, Omori A, Tanaka M, Moniwa N,Ohnishi H, et al: Serum FABP5 concentration is a potential biomarker for residual risk of atherosclerosis in relation to cholesterol efflux from macrophages. Sci Rep 7: 217, 2017.

29. Yeung DC, Wang Y, Xu A, Cheung SC, Wat NM, Fong DY, Fong $\mathrm{CH}$, Chau MT, Sham PC and Lam KS: Epidermal fatty-acid-binding protein: A new circulating biomarker associated with cardio-metabolic risk factors and carotid atherosclerosis. Eur Heart J 29: 2156-2163, 2008. 
30. Song J, Zhang H, Wang Z, Xu W, Zhong L, Cao J, Yang J, Tian Y, Yu D, Ji J, et al: The role of FABP5 in radiation-induced human skin fibrosis. Radiat Res 189: 177-186, 2018.

31. Fei F, Qu J, Li C, Wang X, Li Y and Zhang S: Role of metastasis-induced protein S100A4 in human non-tumor pathophysiologies. Cell Biosci 7: 64, 2017.

32. Grotterød I, Maelandsmo GM and Boye K: Signal transduction mechanisms involved in S100A4-induced activation of the transcription factor NF-kappaB. BMC Cancer 10: 241, 2010.

33. Schneider M, Kostin S, Strøm CC, Aplin M, Lyngbaek S, Theilade J, Grigorian M, Andersen CB, Lukanidin E, Lerche Hansen J and Sheikh SP: S100A4 is upregulated in injured myocardium and promotes growth and survival of cardiac myocytes. Cardiovasc Res 75: 40-50, 2007.

34. Tomcik M, Palumbo-Zerr K, Zerr P, Avouac J, Dees C, Sumova B, Distler A, Beyer C, Cerezo LA, Becvar R, et al: S100A4 amplifies TGF- $\beta$-induced fibroblast activation in systemic sclerosis. Ann Rheum Dis 74: 1748-1755, 2015.

35. Zhao YX, Ho CK, Xie Y, Chen YH, Li HZ, Zhang GY and Li QF: Calcimycin suppresses S100A4 expression and inhibits the stimulatory effect of transforming growth factor $\beta 1$ on Keloid fibroblasts. Ann Plast Surg 81: 163-169, 2018.

36. Donato R: Intracellular and extracellular roles of S100 proteins. Microsc Res Tech 60: 540-551, 2003.

37. Lin H, Andersen GR and Yatime L: Crystal structure of human S100A8 in complex with zinc and calcium. BMC Struct Biol 16: 8, 2016.

38. Bouzidi $\mathrm{F}$ and Doussiere J: Binding of arachidonic acid to myeloid-related proteins (S100A8/A9) enhances phagocytic NADPH oxidase activation. Biochem Biophys Res Commun 325: 1060-1065, 2004.
39. Gebhardt C, Németh J, Angel P and Hess J: S100A8 and S100A9 in inflammation and cancer. Biochem Pharmacol 72: 1622-1631, 2006.

40. Basso D, Bozzato D, Padoan A, Moz S, Zambon CF, Fogar P, Greco E, Scorzeto M, Simonato F, Navaglia F, et al: Inflammation and pancreatic cancer: Molecular and functional interactions between S100A8, S100A9, NT-S100A8 and TGF $\beta 1$. Cell Commun Signal 26: 12-20, 2014.

41. Shabani F, Farasat A, Mahdavi M and Gheibi N: Calprotectin (S100A8/S100A9): A key protein between inflammation and cancer. Inflamm Res 67: 801-812, 2018.

42. Yaundong L, Dongyan W, Lijun H and Zhibo X: Effects of downregulation of S100A8 protein expression on cell cycle and apoptosis of fibroblasts derived from hypertrophic scars. Aesthet Surg J 34: 160-167, 2014.

43. Hessian PA, Edgeworth J and Hogg N: MRP-8 and MRP-14, two abundant $\mathrm{Ca}(2+)$-binding proteins of neutrophils and monocytes. J Leukoc Biol 53: 197-204, 1993.

44. Markowitz J and Carson WE III: Review of S100A9 biology and its role in cancer. Biochim Biophys Acta 1835: 100-109, 2013.

45. Zhong A, Xu W, Zhao J, Xie P, Jia S, Sun J, Galiano RD, Mustoe TA and Hong SJ: S100A8 and S100A9 are induced by decreased hydration in the epidermis and promote fibroblast activation and fibrosis in the dermis. Am J Pathol 186: 109-122, 2016.

(i) (9) This work is licensed under a Creative Commons

Attribution-NonCommercial-NoDerivatives 4.0 International (CC BY-NC-ND 4.0) License. 